\title{
Gobernabilidad en Honduras y Paraguay: reforma pública y cooperación internacional en rupturas presidenciales*
}

\section{Governance in Honduras and Paraguay: Public Reform and International Cooperation during Presidential Breakdowns}

Miguel Gomis-Balestreri*

Recibido: 25 de febrero de 2015

Aprobado: 2 de febrero de 2016

Disponible en línea: 30 de junio de 2016

\section{Resumen}

Desde la tercera ola democratizadora en América Latina, las rupturas presidenciales en la región se han presentado en contextos socialmente opuestos. Los mecanismos constitucionales son diversos, pero han ofrecido reducidas opciones de revocación de mandatos presidenciales. Las rupturas de Paraguay y Honduras llevaron a un intenso clima de polarización de la opinión pública interna y externa. Aunque se conocen los debates sobre la legalidad y las causas de dichas rupturas, quedan condicionantes por analizar. En este artículo se investiga la relación entre la cooperación internacional y las reformas de gestión pública en contextos de ruptura presidencial en Honduras y Paraguay. La investigación revisa

\section{Abstract}

From the third wave of democratization in Latin America, presidential breakdowns in the region have occurred in socially opposite contexts. The constitutional mechanisms are different but have offered reduced options for revocation of presidential terms. The last two ruptures of $\mathrm{Pa}-$ raguay and Honduras led to an intense climate of polarization of the internal and external public. Although we know the debates about the legality and the causes, some conditions of such breaks are still to be analyzed. In this article we seek to determine the relationship between international cooperation and public management reforms in the context of presidential rupture in Honduras and Paraguay. The research reviews

doi:10.11144/Javeriana.papo21-1.ghpr

* Artículo de revisión.

** Politólogo especializado en Iberoamérica por el Instituto de Estudios Políticos de París, magíster en Gobierno y Administración Pública por el Instituto Universitario de Investigación Ortega y Gasset y Universidad Internacional Menéndez Pelayo, magíster en Finanzas y Estrategia por el Instituto de Estudios Políticos de París y doctorando en Ciencia Política y Relaciones Internacionales de la Universidad Complutense de Madrid. Docente de la Pontificia Universidad Javeriana de Bogotá. Consultor en gobernabilidad y gestión pública latinoamericana. Correo electrónico: miguel.gomis@gmail.com 
los sectores, los montos y las fechas de ayuda internacional en paralelo a las reformas para defender la tesis de que los Gobiernos de posruptura presidencial usan las reformas de la gestión pública por medio de la cooperación internacional, con el fin de reforzar su propio statu quo.

\section{Palabras clave}

Honduras; Paraguay; reformas; gestión pública; cooperación internacional; ruptura presidencial

\section{Cómo citar este artículo:}

Gomis-Balestreri, M. (2016). Gobernabilidad en Honduras y Paraguay: reforma pública y cooperación internacional en rupturas presidenciales. Papel Político, 21(1), 249-284. http://dx.doi. org/10.11144/Javeriana.papo21-1.ghpr the sectors, the amounts and dates of international aid in parallel to reforms, in order to defend the thesis that governments after presidential breakdowns tend to use public management reforms through international cooperation to strengthen their own status quo.

\section{Keywords}

Honduras; Paraguay; reforms; governance; international cooperation; presidential breakdowns 


\section{Introducción}

$\mathrm{Al}$ pasear por las calles de Asunción, el visitante tiene en mente un paseo por alguna ciudad centroamericana. Sus calles, su brisa y su suave alboroto. América Central y Paraguay, tan distantes geográficamente, pero sorprendentemente cercanos en su ritmo de vida. Obviamente, esto simplemente es una sensación, una idea de viajero o impresión que queda para el foráneo. Ojo, es idea compartida, no quimera de solo uno. En realidad, hay más cosas en común de lo que uno pudiera pensar. La tentación de esta comparación -que puede ser vista como mínimo heterodoxa- se refuerza cuando se considera que Honduras y Paraguay son de los últimos países latinoamericanos en haber conocido rupturas presidenciales. Aunque con condiciones, tiempos, consecuencias y causas diferentes, las dos naciones son interesantes de comparar por varias razones: en ambas se tiene un modelo económico de desarrollo altamente excluyente, en ambas prevalece desigualdad y extensa pobreza, en ambas ciertas élites se perpetúan en el poder político y económico. A consideración de este contexto, el lirismo del paseo cambia drásticamente y la brisa caliente ya no entusiasma forzosamente tanto.

A vista de que en América Latina las rupturas presidenciales (Llanos y Marsteintredet, 2010) son una práctica institucionalmente confusa, pero repetida desde la tercera ola de democratizaciones, no se puede dejar de recalcar la necesidad de un análisis de este fenómeno a la luz de otras variables. Se debe, pues, considerar, entre otros, los flujos de cooperación internacional, las reformas de gestión pública, los procesos de integración regional o los conflictos de poder entre élites económicas y políticas públicas insertadas en pugnas tanto ideológicas como de dominación estatal. Lo que subyace a la comparación es que los procesos de las rupturas presidenciales - densamente mediatizados en interno y externo- son periodos convulsos que se explican y conectan con actores tanto nacionales como extranjeros.

El análisis se hace aún más apremiante cuando se consideran dos obviedades. Por un lado, es muy probable que sigan ocurriendo rupturas presidenciales en la región debido a los perfiles constitucionales y el ingreso a finales de 2015 de gran parte de Suramérica en un periodo económicamente más complicado que la primera década del siglo XXI. ${ }^{1}$ Por otro lado, el proceso de modernización de los Estados latinoamericanos sigue siendo paradójico e incompleto, con trayectorias cada vez más desemejantes. Sirva de ejemplo y punto de partida de la heterogeneidad la mención de las reformas en América Latina, entre las que siempre se situaron las tan ansiadas, polémicas o inclusive esperpénticas reformas agrarias. Se supone que hoy día es cosa del pasado; casi todos los países de la región han operado modificaciones en sus modelos de producción de manera directa o indirecta varias veces durante el siglo XXI (Chiani y Scartascini del Río, 2009). Mas no casualmente, Honduras y Paraguay siguen teniendo pendiente una repartición más equitativa de la tierra. En el caso

\footnotetext{
${ }^{1} \mathrm{~A}$ fecha de este artículo, Brasil se encuentra al borde de un quiebre presidencial similar.
} 
de Honduras, la desigualdad se ve agravada por las dificultades burocráticas y financieras para el acceso a la tierra (Kay, 2009). En Paraguay, la distribución desigual, consecuencia de la dictadura, ha sido profundizada a causa del modelo "brasiguayo" del agronegocio (Alderete, 2015). Este sistema ha reforzado la pobreza de los pequeños campesinos y, sobre todo, marginado a comunidades indígenas, cuyos derechos son recurrentemente vulnerados (Coordinadora de Derechos Humanos del Paraguay, 2013).

Se piensa no obstante - y con razón- que la cuestión esencial reside en las dudas que ha dejado el actor público: su capacidad de respuesta, su eficacia, su transparencia o inclusive respeto por la democracia, América Latina tiene aún grandes desafíos en gestión pública; ${ }^{2}$ empero, si se quieren entender las dificultades para alcanzar administraciones dinámicas y eficientes, se han de contemplar posibles correlaciones poco estudiadas o entendidas. Las vías de mejora necesitan análisis de contexto y comprensión de los factores desestabilizadores o frenos a la modernización. En resumen: si se examinan las rupturas presidenciales se puede, como quien observa un paciente con síntomas más evidentes, elucidar la relación entre ciertos fenómenos que permitan entender las rupturas presidenciales como periodos extraordinarios pero no escasos.

En este inicio de siglo XXI -e inclusive desde la segunda mitad de la década de 1990-, las reformas para la gobernabilidad son la letanía de moda en la cooperación técnica internacional (Grindle, 2012), aunque con mucho fundamento. No se puede concebir progreso en América Latina sin antes mejorar la eficacia - que aún no forzosamente eficiencia- de los poderes públicos. De hecho, Jorge von Horoch no duda en resumirlo en tres resoluciones para 2015 (forjar gobiernos eficaces, promover gobiernos eficientes y abiertos) (Santiso y Von Horoch, 2015). Ahora bien, en contextos cambiantes y tan inesperados, surgen varios interrogantes: ¿qué relación existe entre los ciclos de reforma pública y los ciclos de inestabilidad política? Y ¿̇qué relación entre los dos anteriores y la cooperación internacional? La relevancia de introducir la cooperación internacional para el desarrollo en la ecuación proviene de que ha sido históricamente usada como una herramienta de la política exterior de las potencias mundiales en apoyo o confrontación a Gobiernos autocráticos o cuestionados (Thyne y Powell, 2014).

Quien quiera entender la relación entre los diferentes factores enunciados deberá partir de varias constataciones. Primero, no todas las reformas de gestión pública están forzosamente ligadas a cooperación técnica, aunque sí guardan casi siempre relación con procesos internacionales (integración, isomorfismo institucional, presiones bilaterales, negociaciones, etc.). Segundo, las contradicciones existentes entre las reformas denotan ausencia o deficiente planificación. Tercero, las rupturas e inestabilidades

\footnotetext{
${ }^{2}$ Se concibe aquí la gestión pública como la planeación, dirección e implementación de acciones en función de metas definidas políticamente con recursos públicos limitados y de la manera más eficiente.
} 
políticas surgen en momentos paradójicos, en los cuales las reformas de gestión pública cobran especial relevancia: 1) para revertir lo que no gustó; 2) para legitimar el nuevo Gobierno, es decir, trabajar en una dimensión simbólica; 3) para implementar cambios que se esperan eficaces; y 4) por réditos, a saber, por interés propio o colectivo cercano.

A la luz de estas aclaraciones, la pregunta que orienta este artículo se circunscribe a una simple formulación: ¿qué relación existe entre la ayuda internacional y las reformas de gestión pública en los contextos de ruptura presidencial? Si bien ya existen estudios que analizan el impacto de la ayuda externa sobre los ciclos de reforma política (Crawford, 2001), no ha habido - a nuestro conocimiento- una reflexión sobre las consecuencias de las más recientes rupturas presidenciales sobre las reformas de gestión pública o la cooperación internacional (Llanos y Marsteintredet, 2010). Obviamente, existen todos los estudios que tratan las ayudas condicionadas de los organismos multilaterales, como el Banco Mundial o el Fondo Monetario Internacional en relación con las reformas neoliberales llevadas a cabo en las décadas de 1980 y 1990 cuando las dificultades de financiamiento fueron la causa de la ayuda externa (mientras que hoy día son consecuencia de rupturas presidenciales).

La relación entre rupturas presidenciales y reformas de gestión pública ${ }^{3}$ es extremadamente relevante a causa de su utilización como punto central de estrategias gubernamentales para dotarse o reforzar su legitimidad. Es decir que las reformas de gestión pública serían instrumentalizadas y usadas por los Gobiernos postruptura presidencial, con el fin de posicionarse frente al statu quo político anterior (así sea para defenderlo o revertirlo).

A vistas del análisis del presente texto y a causa del grado polémico relacionado con las apelaciones descriptivas ( Boyd-Barrett y Boyd-Barrett, 2010), así como la clara dualidad de los sistemas de pensamiento al respecto, se describe en un primer momento el marco teórico seguido del diseño metodológico sustentado en el process tracing. En un segundo momento, se propone la descripción del contexto excepcional (ruptura presidencial) para después analizar la relación entre ruptura presidencial (causa) y flujos de cooperación internacional (mecanismo). Una vez aclarado dicho nexo, se pasa a poner en perspectiva la causa con el resultado (reformas de gestión pública durante o después de la ruptura presidencial, acompañadas por cooperación internacional). Se termina con una discusión de las hipótesis, así como con recomendaciones y pistas para la futura ampliación de esta reflexión.

\section{Ruptura presidencial frente a golpe de Estado}

Los eventos de 2009 en Honduras y 2012 en Paraguay tuvieron profundas consecuencias sociales e institucionales. La perseverancia de los países en las rupturas presidenciales a pesar de la presión internacional dejó claro que los países latinoamericanos están

\footnotetext{
${ }^{3}$ Se entiende por reformas de la gestión pública los cambios en los diseños institucionales, sus reglas de juego o los actores involucrados en la planeación, la dirección y la implementación de las políticas públicas (definidas según Parsons [2007]).
} 
en sendas de modernidad paradójica; guardan viejas costumbres (destitución inesperada), pero con nuevos mecanismos y argumentos (empoderamiento de los congresos nacionales y del sistema judicial). Aunque no son pocos los autores y medios que han hablado de golpe de Estado, el presente análisis parte del concepto de ruptura presidencial a causa de la dimensión tanto constitucional como procedimental. El exhaustivo examen comparativo de Brewer-Carías (2009) deja bien claro que frente a los enfoques más extremos o ideológicos (como Briceño [2011]) hay que integrar toda una batería de matices. Eso no quita que sean periodos de ajuste de debatible constitucionalidad o legalidad debido a las falencias o rigideces del ordenamiento institucional y político.

Ahora bien, la validez del concepto de ruptura presidencial para América Latina depende de su relación con la noción de golpe de Estado. Se defiende aquí que ambos episodios pueden acogerse a la tipología de ruptura presidencial sin por ello negar que alcancen a ser igualmente considerados como golpes de Estado en función de otros criterios. Como lo razonan varios autores (en especial Serrafero [1996]), el golpe de Estado puede ser un mecanismo que forja ruptura institucional. Sería erróneo ver el golpe de Estado únicamente como un resultado u objetivo per se: es ante todo causa y mecanismo para los objetivos de aquellos que dirigen y facilitan el quiebre presidencial. Definir los casos de Honduras y Paraguay como golpes de Estado sería reducir la complejidad de dichos periodos a una discusión basada en matrices de lectura anticuadas por binomiales (y simplificadoras, como Briceño [2011]).

\section{La ruptura presidencial como concepto}

Existe una amplia literatura sobre rupturas presidenciales que ha tratado de elaborar un concepto teórico a partir de las diferencias y similitudes de las eventos latinoamericanos que se puedan acoger bajo esa categorización. Pérez-Liñán (2012) ha llevado a cabo uno de los análisis más recientes y completos sobre el fenómeno. Según él, existirían dos tendencias explicativas en la literatura: los movimientos sociales y los factores institucionales (como la parlamentarización de los regímenes). Pérez-Liñán sustenta que estaríamos en realidad ante una combinación que es más acertada ver desde dos niveles. Primero, están los actores y las situaciones que representan una amenaza para el presidente. Segundo, están los actores y las situaciones que representan un escudo para el presidente. Lo interesante del enfoque de Pérez-Liñán reside en el hecho de que las movilizaciones sociales no son forzosamente un argumento que explique la ruptura presidencial, puesto que también explica la ausencia de ruptura. La ventaja de la visión heurística de Pérez-Liñán reside en explicar tanto las rupturas con movilización como las que no la han tenido (recordemos que en el caso de Zelaya y de Lugo hubo antes y después de la ruptura presidencial).

Existen otros aportes por considerar, como el de Serrafero (1996), para quien la ruptura es sobre todo un quiebre institucional sustentado en la movilización ciudadana, 
en la que la destitución se da por amenaza o cumplimiento de empeachment. Para Hagopian (2006), la interrupción presidencial se da por presión de actores bien definidos (indígenas, descontentos, élites económicas, etc.) que se movilizan y judicializan las instituciones políticas, con el fin de mostrar la salida al presidente. En el caso de la caída presidencial, según Hochstetler (2006), el detonador sería un contexto de fracaso de las políticas o corrupción junto con una incapacidad para los partidos políticos para canalizar la indignación del electorado. Desde la interrupción presidencial, según Valenzuela (2008), el personalismo y la prepotencia del ejecutivo frente al legislativo ahondan las tensiones y pueden incluso terminar en represión de movilizaciones.

Para Llanos y Marsteintredet (2010), una presidencia interrumpida es aquella en la cual "un cargo elegido es forzado a una salida extraordinaria del poder antes del final del término de su mandato fijado constitucionalmente" [La traducción es mía]. Según estos autores, la diferencia entre la ruptura presidencial y los golpes de Estado del pasado latinoamericano es que la primera lleva forzosamente a un quiebre del orden democrático (aunque muchas veces está en una zona "gris" intermedia).

Más allá de los debates puramente constitucionales sobre los artículos pétreos (Brewer-Carías, 2009), estas alternativas parten de los peligros del presidencialismo latinoamericano explicitados por Linz o Valenzuela (2008). El debate sobre las rupturas presidenciales se inició en torno a la oposición entre parlamentarismo y presidencialismo, discusión que se ha nutrido naturalmente de las tesis de Sartori (1994) (para quien el presidencialismo se caracterizaría por la imposibilidad de que el Congreso retire al presidente del cargo) u O’Donnell (1994), para quien la democracia “delegativa” aumentaba el riesgo de inestabilidad latinoamericana. Es evidente que la rigidez de los sistemas presidenciales y la insuficiencia de los check and balances han favorecido la inestabilidad. Esta última ha sido profundizada por el multipartidismo parlamentario (con baja institucionalización y disciplina de voto los partidos políticos) donde las coaliciones pueden poner en peligro la viabilidad de los Gobiernos (Chasquetti, 2001). La confrontación entre legislativo y ejecutivo se nutre de las amplias capacidades legisladoras de los presidentes, los cuales tienden a reforzar estilos de dirección política fuerte que genera enérgicas aprehensiones. Se añade a todo este escenario el papel de los ejércitos, cuyo rol lleva a describir las democracias como tuteladas (Kruijt, 2001) (han aceptado las reglas de juego democráticas, pero ejercen una vigilancia indirecta sobre los procesos políticos), en especial en los países donde tradicionalmente se han atribuido un papel de salvaguarda social (Honduras, Paraguay, Venezuela, República Dominicana, entre otros).

\section{El golpe de Estado como noción acotada}

Las definiciones de ruptura presidencial se alejan claramente de las de golpe de Estado. Según Thyne y Powell (2014), estos tienen efectos contraintuitivos, donde pueden abrir 
un proceso de democratización y, cuando fracasan, son una fuerte señal de la necesidad de reformas. De hecho, Varol (2012) sostiene esta misma tesis al calificar algunos golpes como democráticos por sus objetivos y valores. Estos matices significan tres argumentos para preferir el concepto de ruptura presidencial. Primero, la discusión sobre la calificación del golpe de Estado no es de resultado sino de proceso. Segundo, la posición de Thyne y Powell (2014) muestra que la disputa sobre la calificación no puede estar orientada por una valoración positiva o negativa en función de prejuicios. Tercero, según Thyne y Powell la mayoría de los golpes de Estado suceden en regímenes no democráticos, situación difícilmente asimilable a Honduras y Paraguay donde sí hubo elecciones y garantías mínimas democráticas (según los criterios de Morlino [2004]), a pesar de las falencias y debilidades en la separación de poderes o la competición electoral. De hecho, según Casper y Tyson (2014), las élites tienden a sobre reaccionar a las protestas ciudadanas en países donde hay libertad de prensa (la movilización ciudadana y de élites serían consecuencia).

Yendo más lejos, según Thyne y Powell (2014), el golpe de Estado es aquel intento "ilegal y abierto, de militares u otras élites pertenecientes al aparato del Estado para expulsar al ejecutivo [La traducción es mía]”. El golpe de Estado se caracterizaría por tres fenómenos. El primero es que el golpe debe buscar relevar el jefe de ejecutivo, lo cual excluye otro tipo de acciones que ponen en duda el liderazgo, pero que no buscan cambiar el régimen político. El segundo es que los perpetradores provienen de las élites que forman parte del aparato estatal, en general oficiales del Ejército. Por ello, no es sorprendente que Powell (2012) se centre exclusivamente en el Ejército al analizar los mecanismos institucionales creados en las democracias para prevenir los golpes de Estado. Tercero, las tácticas deben de ser ilegales y hacer que el golpe de Estado sea distinto de la presión política que lleva a la renuncia. Estos tres criterios se explicarían por una evaluación de coste-beneficio de los perpetradores sobre la progresión del statu quo.

\section{Categorización de Honduras frente a Paraguay}

A la luz de las definiciones de los dos conceptos, definir los eventos de Honduras y Paraguay como rupturas presidenciales no es inexacto ni contradictorio. En cuanto a Honduras, el país no había conocido quiebre en contexto de democracia consolidada (desde 1982). Al opuesto, Paraguay ya había tenido un episodio con Raúl Cubas Grau (Fretes, 2012; Pérez-Liñan, 2000). Empero, como bien lo recuerda Abente-Brun (2007), Paraguay ha conocido, además, inestabilidades cercanas a la ruptura presidencial, con periodos de juicios y acusaciones graves relacionadas con intentos de golpe de Estado e inclusive asesinatos políticos. Por añadido, el desequilibrio no es, claramente, una cuestión intrínsecamente nacional, puesto que, como lo recuerda Prera (2012), en Centroamérica también se han de considerar los efectos y contextos de la integración económica. Esto es relevante por las estrategias de cooperación internacional que se 
llevan desde y para los dos países (Sistema de la Integración Centroamericana para Honduras, Mercado Común del Sur y Unión de Naciones Suramericanas para Paraguay).

Llanos y Marsteintredet (2010) hacen un análisis extensivo del caso deZelaya revisándolo en Marsteintredet, Llanos y y Nolte (2013) a la luz de los eventos de Paraguay, que transitó por cauces legales a pesar de los argumentos esgrimidos del libelo acusatorio (López, 2012). Si bien en Honduras el Ejército participó en la expulsión orquestada por una élite en efecto perteneciente al estamento, lo cierto es que el debate surge sobre la combinación de medidas legales e ilegales en el proceso. Es evidente que en Honduras el papel de los militares imposibilitaría según Hochstetler y Samuels (2011) su clasificación como ruptura presidencial. Ahora bien, eso no quita que la Constitución hondureña amparara las acciones y haya sido una herramienta hábilmente diseñada para evitar la puesta en duda del statu quo de la élite según Waring (2014). En Paraguay, el cambio no fue stricto sensu en ningún momento ni ilegal ni anticonstitucional y probablemente se haya dado un proceso de aprendizaje (Mustapic, 2006). ${ }^{4}$ En ambos casos es debatible que el objetivo de las élites fuera el cambio de régimen, sino más bien el cambio del sistema político según los criterios de Easton (1957).

\section{El golpe de Estado como ruptura presidencial}

La propuesta de la ruptura presidencial presenta cuatro fortalezas que originan cuatro justificaciones para su uso para los casos de Honduras y Paraguay. La primera fortaleza es que se diferencia entre las caídas de presidentes antes y después de la tercera ola de democratizaciones, puesto que integra el papel de los limitantes y las vicisitudes de los mecanismos para la revocación de mandatos presidenciales. La segunda es que contempla igualmente los atenuantes, como la pérdida de confianza constitucional o el grado de movilización social para el cambio. La tercera fortaleza es que permite asimilar todos los quiebres presidenciales latinoamericanos y no dar por sentado de antemano que sus causas son distintas. La cuarta fortaleza es que no excluye técnicamente la posibilidad de que el evento pueda ser calificado como golpe de Estado.

La primera justificación para su uso en este estudio es que el debate pasa de uno procedimental a otro causal. La segunda es que permite salir de una visión ideologizada heredera de la guerra fría. La tercera es que el concepto de golpe de Estado favorece ver la gravedad de unos quiebres mientras infravalora la de otros. La cuarta es que sirve para re-enfocar la discusión y favorecer una visión longitudinal en la región.

Ante el presente estudio se retiene, entonces, que la ruptura presidencial supone un cambio de Gobierno nacional que irrespeta los mecanismos o tiempos democráticos (legales o tradicionales) con consecuencias y repercusiones tanto internas (inestabilidad

${ }^{4}$ La diferencia entre Honduras y Paraguay residiría entonces en que Zelaya desafió la legalidad infravalorando la posibilidad de su expulsión de la presidencia. 
social y económica, aunque favorecen estabilización política) como externas (genera opinión y acciones internacionales).

\section{Enfoque y diseño metodológico}

El process tracing busca sistematizar la búsqueda de relaciones causales en estudios de caso (Bennett y Checkel, 2014). Según Collier (2011), el conocimiento previo es indispensable para ser capaces de proponer inferencias causales (es decir, conocer los límites entre conceptos), para proponer regularidades empíricas periódicas (patrones que describen relaciones entre fenómenos), así como para elaborar una teoría descriptiva (relación entre regularidades y fenómenos), además de un modelo explicativo (explicación del porqué de las regularidades).

Desde el process tracing, las hipótesis por verificar pueden ser de doble índole: unas aseveran una inferencia descriptiva sobre lo que pasa, otras buscan establecer causalidades entre procesos que se cree que han sucedido. Para deducir la existencia de un evento o fenómeno no observado, hay que tener certeza de que el caso por estudiar reúne las condiciones para la causa o el resultado (Mahoney, 2012). Teniendo en cuenta este enfoque metodológico, los puntos centrales de esta investigación se pueden resumir como sigue (tabla 1).

Tabla 1. Resumen de los datos centrales de la investigación

\begin{tabular}{|l|l|}
\hline Pregunta & $\begin{array}{l}\text { ¿Las rupturas presidenciales tienen impactos en los ciclos de reforma } \\
\text { de gestión pública con cooperación internacional? }\end{array}$ \\
\hline Subpregunta & $\begin{array}{l}\text { ¿Las reformas con apoyo internacional forman parte de estrategias } \\
\text { políticas de los Gobiernos resultantes de rupturas presidenciales? }\end{array}$ \\
\hline Hipótesis & $\begin{array}{l}\text { Los Gobiernos de posruptura presidencial usan las reformas de la } \\
\text { gestión pública gracias a cooperación internacional, con el fin de } \\
\text { reforzar su propio statu quo. }\end{array}$ \\
\hline Resultado & $\begin{array}{l}\text { Aumento en el número de reformas institucionales en periodo } \\
\text { posruptura presidencial. }\end{array}$ \\
\hline Mecanismo & Modificación en los ciclos de cooperación internacional. \\
\hline Causa & Estrategia del Gobierno frente al statu quo político. \\
\hline Variable dependiente & Reformas en gestión pública. \\
\hline Variable independiente & $\begin{array}{l}\text { Ciclos de cooperación internacional en contexto de ruptura } \\
\text { presidencial. }\end{array}$ \\
\hline
\end{tabular}

Dando por supuesto que desde el process tracing la relación causa-mecanismoresultado se debe leer en un solo sentido (las reformas no sirven de medición para calificar los eventos de ruptura), las hipótesis sobre las relaciones enunciadas se pueden completar con las afirmaciones siguientes: 1) las rupturas presidenciales aceleran reformas de gestión pública (tanto las que llevan a la ruptura como las que nacen de ella) y 
2) la cooperación internacional tiene un efecto paradójico al profundizar la intensidad de las reformas escogidas tanto durante como después de su cese o revisión.

Con el fin de llevar a cabo la elucidación de la pregunta, se ha adoptado una estrategia comparativa que contrasta datos cuantitativos con ciclos de reforma. Se han recopilado todos los proyectos aprobados por tres organismos multilaterales (el Banco Mundial, el Programa de las Naciones Unidas para el Desarrollo el Banco Interamericano de Desarrollo) y un actor bilateral, a saber, la Agencia de los Estados Unidos para el Desarrollo Internacional (USAID). Se han clasificado en función de su ámbito de acción y se han recopilado las fechas y los montos de aprobación.

En un segundo momento, se ha recopilado información sobre las leyes, los decretos y las resoluciones que modifican el funcionamiento de la gestión pública en ambos países. Se han clasificado por orden cronológico, con el fin de poder, en un tercer momento, comparar la progresión de las reformas con el de la cooperación internacional (tanto todos los proyectos juntos como con solo los de reforma y modernización del Estado).

Está claro que esta metodología tiene limitaciones a causa de la imposibilidad de contar con los montos exactos de los proyectos de la USAID, así como la incapacidad de conseguir la fecha de finalización de muchos proyectos. ${ }^{5} \mathrm{Al}$ mismo tiempo había imposibilidad de tener la evolución de los desembolsos para un gran número de proyectos al no existir uniformidad de criterios, ${ }^{6}$ y hay actores con volúmenes significativos que son de difícil consideración a causa del limitado acceso informativo (parte de los datos de flujos financieros negociados son confidenciales o aun no son públicos).

La investigación es exploratoria y asume su intrínseco carácter limitado. Se ha preferido comunicar las conclusiones, para que, en posibles trabajos posteriores, se tomen en cuenta las pistas de reflexión ofrecidas aquí. Una vez explicado el marco teórico y el enfoque metodológico, se pueden describir las fases que siguen. Primero, se ha de explicar el contexto de las rupturas presidenciales, con el fin de entender en qué son comparables. Segundo, se analiza la relación entre rupturas presidenciales y cooperación internacional (causa-mecanismo). Tercero, se trata de reflexionar sobre la relación entre las rupturas presidenciales (causa) y las reformas de gestión pública (resultado).

\section{Convergencias entre Honduras y Paraguay}

Con el fin de describir el contexto de ambos países, en un primer momento, se revisarán los puntos comunes o convergentes entre ambos países. Antes se propone una síntesis

\footnotetext{
${ }^{5}$ Un gran número son prorrogados y la información no es actualizada de manera pertinente en las webs institucionales.

${ }^{6}$ No parece que se apliquen reglas comunes, puesto que un mismo organismo, a veces, ofrece los detalles de desembolso y otras veces no.
} 
de los diferentes periodos y presidentes relacionados con las rupturas presidenciales en Honduras y Paraguay (tabla 2).

Tabla 2. Periodos presidenciales de Honduras y Paraguay en los contextos de ruptura presidencial

\begin{tabular}{|c|c|c|c|c|c|}
\hline \multicolumn{2}{|r|}{$\begin{array}{l}\text { País/tipo de } \\
\text { Gobierno }\end{array}$} & $\begin{array}{c}\text { Gobierno } \\
\text { democrático }\end{array}$ & $\begin{array}{c}\text { Ruptura } \\
\text { presidencial }\end{array}$ & \begin{tabular}{|c|} 
Gobierno \\
posrupturas \\
presidenciales 1
\end{tabular} & $\begin{array}{c}\text { Gobierno } \\
\text { posrupturas } \\
\text { presidenciales } 2\end{array}$ \\
\hline \multirow{3}{*}{ 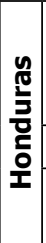 } & Presidente & $\begin{array}{l}\text { José Manuel } \\
\text { Zelaya Rosales }\end{array}$ & $\begin{array}{l}\text { Roberto } \\
\text { Micheletti Bain }\end{array}$ & Porfirio Lobo Sosa & $\begin{array}{l}\text { Juan Orlando } \\
\text { Hernández } \\
\text { Alvarado }\end{array}$ \\
\hline & Fecha de inicio & $27 / 01 / 2006$ & $29 / 06 / 2009$ & $27 / 01 / 2010$ & $27 / 01 / 2014$ \\
\hline & $\begin{array}{c}\text { Fecha de } \\
\text { finalización }\end{array}$ & $29 / 06 / 2009$ & $27 / 01 / 2009$ & $27 / 01 / 2014$ & $26 / 01 / 2018$ \\
\hline \multirow[t]{3}{*}{ त्ञ } & Presidente & \begin{tabular}{|l|} 
Fernando \\
Armindo \\
Lugo Méndez \\
\end{tabular} & $\begin{array}{l}\text { Luis Federico } \\
\text { Franco Gómez }\end{array}$ & $\begin{array}{l}\text { Horacio Manuel } \\
\text { Cartes Jara }\end{array}$ & - \\
\hline & Fecha inicio & $15 / 08 / 2008$ & $22 / 06 / 2012$ & $15 / 08 / 2013$ & - \\
\hline & $\begin{array}{c}\text { Fecha de } \\
\text { finalización }\end{array}$ & $22 / 06 / 2012$ & $15 / 08 / 2013$ & $14 / 08 / 2018$ & - \\
\hline
\end{tabular}

Existen puntos de encuentro entre ambos procesos que nos sugieren la idoneidad de la comparación desde contextos institucionales, políticos e inclusive sociales. En ambos casos, el apoyo parlamentario para destituir a los presidentes fue amplio y los procesos fueron extremadamente expeditivos, y conincidieron en el último tercio de sus mandatos. Los dos presidentes enfrentaron una pérdida de confianza drástica de las élites (materializado en el abandono por parte de sus partidos o aliados), y el caso de Zelaya es el más claro. Al relacionar el desgaste (que dura varios años) de la popularidad o el ascenso de la polarización y la coincidencia en la rupturas presidenciales hacia el final de los mandatos, surge la pregunta que también se tratará de elucidar: ¿por qué las élites no esperaron al final del mandado para movilizarse?

Desde el punto de vista de los modelos y condicionantes económicos se puede ver que los dos países cuentan con grandes desigualdades sociales, donde la prevalencia de la pobreza sigue siendo muy alta. Según la Comisión Económica para América Latina y el Caribe (Cepal, 2014), en 2012, Honduras tenía 71 \% de incidencia de pobreza multidimensional y Paraguay 50 \%, habiendo conocido este último una trayectoria de disminución mucho más marcada que Honduras. Esto es coherente con lo que explica Abente-Brun (2012), quien contrasta el crecimiento de Paraguay con las dificultades para reducir la desigualdad, sobre todo con un presidente que no tenía el suficiente control político como para consolidar su proyecto reformista. El mismo Abente-Brun (2007) ya había ligado el surgimiento del liderazgo de Lugo con la incertidumbre económica que prevaleció durante el mandato de Duarte Frutos. De la misma manera, la preocupante perpetuación 
de la pobreza en Honduras (Macías, Ogando y Rodríguez, 2009) tiene que ser tomada en cuenta para explicar el amplio apoyo social y el inesperado giro - políticamente rentable- de Zelaya hacia políticas mucho más inclusivas. Es obvio que la mala situación económica fortaleció la ilusión de que Lugo o Zelaya representarían una ruptura en las políticas públicas sociales.

El debate sobre el factor económico no se restringe, pues, a explicar el porqué del surgimiento de estos dos liderazgos, sino también de su caída. En ambos casos, las políticas progresistas ponían en peligro ciertos actores dominantes (el statu quo) que no dudaron en aliarse con élites políticas más conservadoras. La relación entre élites económicas y políticas está lejos de ser un secreto en ambos países. Empero, lo que hay que recalcar es que la gran desigualdad y violencia tienen, como lo especifica Gómez Bueso (2007), una consecuencia sobre la plena funcionalidad de los derechos fundamentales de los ciudadanos. Es clave comprender que la dimensión de la pobreza y la desigualdad también condicionan las presiones y los métodos de los movimientos sociales, además del mal funcionamientos del Estado (O’Donnell, 2004).

La pobreza conlleva igualmente exclusión geográfica en Honduras (Pine y Vivar, 2011) aparte de las limitaciones a la hora de la planificación del urbanismo y de la gestión del territorio, como en Paraguay (Flores López, 2009). Paralelamente, la exclusión nutre fenómenos comunes a Honduras y Paraguay, como lo son los importantes flujos migratorios, ${ }^{7}$ las remesas derivadas de dichos trabajadores que impactan en los mercados laborales de origen (Gómez y Bologna, 2013; Medina y Franco, 2006), además de los procesos regionales (Gómez, 2014). Huelga decir que dichos movimientos implican impactos en los países de destino, con diásporas que tienen un papel económico y financiero cada vez más relevante (Orozco, 2003), aparte del impacto en los países de tránsito y de la integridad física misma de los migrantes (López Recinos, 2013). Las similitudes económicas no se paran aquí. Habría también que considerar la estructura del sector agrícola, el acceso deficiente a sistemas básicos, como salud y educación, o inclusive los fenómenos de indigencia periurbana.

Desde el punto de vista de la capacidad del Estado y del funcionamiento democrático, ambos tienen claras debilidades y disfunciones institucionales. Abente-Brun (2012) repasa la evolución de la estatalidad en Paraguay y subraya la necesidad de reforzar su gobernabilidad democrática. Los fenómenos más comunes de debilidad institucional son igualmente visibles en Honduras, donde Taylor-Robinson (2006) liga de acertada manera la evolución de las capacidades gubernativas con los cambios en los procesos y

${ }^{7}$ Hacia los Estados Unidos para los hondureños (Pérez, De la Rosa y Pellandra, 2012), hacia Argentina y España en el caso de los paraguayos. 
resultados electorales entre 1982 y 2005. Algo parecido hace López (2014) al revisar la evolución de la legislación electoral en Paraguay desde la dictadura.

Las falencias en la gestión pública son de hecho ampliamente revisadas en las estrategias de colaboración que elabora el Banco Mundial con estos dos países. ${ }^{8}$ Evidentemente, las rupturas no solo tienen consecuencias en la institucionalidad, sino también en los procesos, los actores y las reglas de juego. La destitución de Lugo representó una interrupción en dinámicas de consolidación democrática (Duarte, 2013) tras decenios de bipartidismo imperfecto. Este podría parecer un punto de divergencia entre los dos casos sin serlo de manera definitiva. Aunque Zelaya pretendiera romper la legalidad a través de la cuarta urna, su focalización en la participación podría ser asimilada -con cautela, eso sí- a una apertura del sistema político.

Lopes (2007) amplía su estudio haciendo un análisis crítico sobre la democracia en la región y tratando de entender el isomorfismo institucional. Para este autor, la consolidación democrática no se ha dado fundamentalmente por presiones sociales, sino porque las relaciones económicas internacionales no tenían objetivos contradictorios con la democratización. La inestabilidad en las ideas políticas y la distancia entre lo prometido y lo hecho lleva a pensar que las democracias latinoamericanas se explican en gran parte por las consecuencias que generan en las relaciones económicas internacionales en sí. Los procesos que se verían así afectados cubren los intercambios comerciales, las inversiones y los procesos de integración. Que las democracias paraguaya y hondureña hayan sido interrumpidas en un proceso de consolidación democrática guardaría entonces relación con un contexto más amplio. Bien es sabido que los intereses de las trasnacionales en ambas naciones probablemente hayan desempeñado un papel relevante a la hora de animar los opositores políticos para llevar a cabo las rupturas presidenciales. En los dos países, las políticas ponían en duda el statu quo económico y por ende político. Lo que hay que retener es que las dos naciones latinoamericanas tienen paralelismos, consecuencia de su debilidad estatal y de la trayectoria de sus sistemas de partidos políticos.

Ahora bien, desde lo que es precisamente la evolución y las características del sistema de partidos políticos que se acaba de mencionar, no se puede dejar de lado lo que nos enseñan Alcántara y Freidenberg (2001), además de Alcántara et al. (2006), ${ }^{9}$ sobre la progresión de los sistemas de partidos políticos en América Latina, y en especial en Honduras y Paraguay. Si se resumen los aportes de estos autores, además de los apuntes de Garretón (2002), se puede afirmar: 1) Paraguay y Honduras han conservado un sistema predemocrático o heredero de la época de las oligarquías; 2) la perpetuación de los partidos clásicos no ha impedido el surgimiento de nuevos partidos; 3) en el sistema

\footnotetext{
${ }^{8}$ Ambas disponibles en http://documentos.bancomundial.org/curated/es/home

9 Tenemos igualmente en consideración los aportes de Alcántara-Santuario y Marín-Fuentes (2013), Alcántara Sáez (2008, 2004), Freidenberg y Alcántara Sáez (2009), Freidenberg (2006), Freidenberg y Levitsky (2007).
} 
sobreviven tanto partidos clásicos como recientes, y los más nuevos tienen dificultades para entrar en alternancia de poder; y 4) la transformación del sistema de partidos hondureño y paraguayo ha sido mucho más tardía que el resto de América Latina.

Cuando José Manuel Zelaya resultó electo por el Partido Liberal frente al Partido Nacional nadie podía imaginar que el presidente terminaría perdiendo el apoyo de su propio partido. Del mismo modo, cuando Fernando Armindo Lugo fue elegido por la Alianza Patriótica para el Cambio ${ }^{10}$ con el apoyo del Partido Liberal Radical Auténtico frente al hegemónico Partido Colorado, nadie podía imaginar que el presidente terminaría perdiendo el apoyo de tantos aliados políticos. A este nivel, el análisis de Chasquetti (2001) en torno a las coaliciones como factor de estabilidad de los presidencialismos multipartidistas es extremadamente acertado, y puede inclusive ampliar la lógica a causa de la multiplicación de facciones internas en los partidos dominantes.

La estabilidad de los sistemas de partidos en Honduras y Paraguay parecía tener elementos distintivos, como lo explica Ajenjo (2007) en el caso de Honduras. No se podía, a vista de esa estabilidad, presagiar: 1) el distanciamiento de Zelaya frente al discurso de su propio partido, 2) el distanciamiento de Zelaya frente a su propia campaña presidencial y 3) la movilización conjunta de los dos principales partidos hegemónicos para destituir a Zelaya. La transformación que quería llevar a cabo Zelaya fue abortada, porque las élites querían contener el cambio para que no pasara a mayores. Esa estabilidad del sistema de partidos es la misma que origina la elección de Lugo como un revulsivo (Brugnoni, 2009) frente a un Partido Colorado que había sido incapaz de reestructurarse (Duarte, 2012). El tipo de liderazgo de Zelaya (Figueroa, 2011), así como el de Lugo, facilitaron que la ruptura del sistema de partidos se consolidara. No en vano, después de las rupturas presidenciales en Honduras, el bipartidismo vio cómo surgían cuatro nuevos partidos ${ }^{11}$ y cómo era capaz de recuperarse electoralmente (Otero, 2013), al redefinirse frente a sus nuevos oponentes (Juste de Ancos, Soler y Ortí, 2014). Del mismo modo, en Paraguay, el Partido Colorado ha llevado una vez más su candidato Horacio Cartes a la presidencia. Probablemente haya que integrar en esta capacidad de recuperación la existencia de una fuerte identificación electoral, además de fraude electoral, un triste pero real punto en común. En Honduras, la contestación y el clima de fraude ha estado claramente vinculado con la extrema polarización del electorado y de los medios de comunicación (Sosa, 2014). En Paraguay, el fraude viene ligado a un sistema de partidos políticos tradicional, que opera en un contexto institucional con bajos incentivos reales frente al fraude (López, 2015), además de poca atención o interés internacional.

\footnotetext{
${ }^{10}$ Que ha dado lugar a la concertación de partidos llamada Frente Guasú.

${ }^{11}$ Entre ellos el Partido Libre, nacido del Frente Nacional de Resistencia Popular y que postularía a Xiomara Castro para las elecciones del 24 de noviembre de 2013.
} 
En resumen: en ambos casos no se estaba en situación de debilidad o minoría electoral que pusiera en duda la viabilidad del mandado. La pérdida de apoyos fue justamente por amenazar el statu quo político. Zelaya se distanció de las élites políticas tradicionales y Lugo aumentó el incentivo para que el Partido Liberal estimara más beneficioso defender el antiguo statu quo (dominado por el Partido Colorado) que apoyar uno nuevo (además de por fin hacerse con la presidencia, así no fuera un mandato completo).

Superando la dimensión económica y política, se puede igualmente mencionar que Honduras y Paraguay comparten otros fenómenos que en general se olvidan. Ambos han tenido conflictos territoriales que han desempeñado funciones identitarias. Honduras tuvo su conflicto con Guatemala e injerencias estadounidenses (García, 2009), además de la bien conocida guerra del fútbol (Gerstein, 1971), cuyas reminiscencias siguen patentes con el conflicto fronterizo del golfo de Fonseca (Medina, 2013). Paraguay sustentó parte de su nacionalismo desde discursos que justificaban el aislamiento y el heroísmo por la independencia de la Triple Alianza (Brezzo, 2010). En ambos casos, la conflictiva relación con los vecinos ha sido un factor de fortalecimiento de los sistemas de partidos políticos y perpetuación de las élites. En efecto, los conflictos han sido y son usados como catalizadores e instrumentos de cohesión nacional según Domínguez (2003).

Para terminar, no se puede dejar de lado un fracasado liberalismo reformador, que explicaría, según Mahoney (2011), la ausencia del ascenso de una burguesía bien diferenciada de las oligarquías decimonónicas y el ausente surgimiento de proyectos de gestión pública con una visión de país integradora. De hecho, no es casualidad que Honduras y Paraguay hayan tenido una prolongada historia de negación y ausente protección de sus comunidades indígenas, a pesar de contar con claras minorías, como los garífunas en Honduras (Mollett, 2006) y los grupos étnicos emparentados con la lengua nacional guaraní en Paraguay (Coordinadora de Derechos Humanos del Paraguay, 2013).

\section{Relación entre rupturas presidenciales y cooperación internacional}

La pregunta de esta investigación trata de buscar las relaciones entre ciclos y para tal fin se busca esclarecer de manera escalonada su evolución antes, durante y después de las rupturas presidenciales de la cooperación internacional y de las reformas de gestión pública. Para poder construir el análisis, se parte de los datos estadísticos obtenidos, recopilados de manera sintética en la tabla 3 . 


\section{Tabla 3. Observación estadística de los proyectos de cooperación internacional aprobados}

\begin{tabular}{|c|c|c|c|c|c|c|c|c|}
\hline & \multicolumn{4}{|c|}{ Honduras } & \multicolumn{4}{|c|}{ Paraguay } \\
\hline & 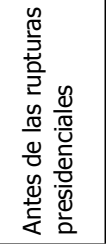 & 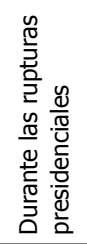 & 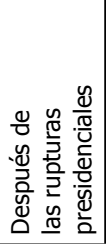 & 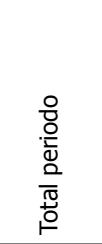 & 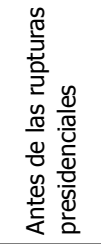 & 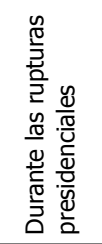 & 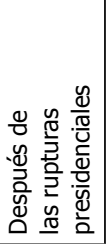 & $\begin{array}{l}\frac{0}{7} \\
\frac{0}{2} \\
\frac{0}{\pi} \\
\frac{\pi}{0}\end{array}$ \\
\hline N. ${ }^{\circ}$ proyectos & 82 & 2 & 86 & 171 & 95 & 25 & 47 & 167 \\
\hline$\%$ proyectos & 47.95 & 1.17 & 50.29 & 100 & 56.89 & 14.97 & 28.14 & 100 \\
\hline Monto total & 780.27 & 2.99 & 843.87 & 1627.13 & 1031.09 & 311.68 & 695.59 & 2038.37 \\
\hline Monto promedio & 6.12 & 2.99 & 12.23 & 10.7 & 12.13 & 12.46 & 14.79 & 12.98 \\
\hline Monto mediano & 0.6 & 2.99 & 0.9 & 0.75 & 0.7 & 0.62 & 0.5 & 0.6 \\
\hline $\begin{array}{l}\% \text { montos sobre el } \\
\text { periodo entero }\end{array}$ & 47.95 & 0.18 & 51.86 & 100 & 50.58 & 15.29 & 34.12 & 100 \\
\hline $\begin{array}{l}\text { N. }{ }^{\circ} \text { proyectos de reforma } \\
\text { y modernización del } \\
\text { Estado }\end{array}$ & 18 & 0 & 23 & 41 & 27 & 5 & 9 & 41 \\
\hline $\begin{array}{l}\text { N. }{ }^{\circ} \text { proyectos reforma } \\
\text { y modernización del } \\
\text { Estado/total proyectos }\end{array}$ & $21.95 \%$ & $0.00 \%$ & $26.74 \%$ & $23.98 \%$ & $28.42 \%$ & $20.00 \%$ & $19.15 \%$ & $24.55 \%$ \\
\hline $\begin{array}{l}\text { Monto total proyectos } \\
\text { reforma y modernización } \\
\text { del Estado }\end{array}$ & 264.87 & 0 & 38.9 & 303.77 & 230.07 & 1.3 & 102.6 & 333.97 \\
\hline $\begin{array}{l}\text { Montos proyectos reforma } \\
\text { y modernización del } \\
\text { Estado/total proyectos }\end{array}$ & $33.95 \%$ & $0.00 \%$ & $4.61 \%$ & $18.67 \%$ & $22.31 \%$ & $0.42 \%$ & $14.75 \%$ & $16.38 \%$ \\
\hline
\end{tabular}

Nota:

Precisiones metodológicas

1. Todos los montos están en millones de dólares estadounidenses.

2. No hemos conseguido los flujos exactos de los proyectos de la USAID, por lo que no han sido integrados en los cálculos sobre montos.

Para Honduras:

1. "Antes de las rupturas presidenciales" equivale al periodo de $01 / 01 / 2007$ a $28 / 06 / 2009$.

2. "Durante las rupturas presidenciales" equivale al periodo de $28 / 06 / 2009$ a $27 / 01 / 2009$.

3. "Después de las rupturas presidenciales" equivale al periodo de $28 / 01 / 2009$ a 31/12/2011. Para Paraguay:

1. "Antes de las rupturas presidenciales" equivale al periodo de $01 / 01 / 2010$ a 22/06/2012.

2. "Durante las rupturas presidenciales" equivale al periodo de $23 / 06 / 2012$ a $25 / 08 / 2013$.

3. "Después de las rupturas presidenciales" equivale al periodo de 26/08/2013 a 31/12/2014.

Como bien se puede observar, se han hecho los cálculos diferenciando tres periodos por país (antes, durante y después de las rupturas presidenciales), además de recopilar los datos brutos y sacar los porcentajes respectivos. Es evidente que los periodos no contienen el mismo número de días a causa de que las rupturas presidenciales no han durado lo mismo. ${ }^{12}$

12 Metodológicamente, se habría tenido que comparar con periodos idénticos en el antes y después del Gobierno de posruptura, por lo que se ha preferido establecer un rango de dos años antes y después de su fecha exacta. 
Durante el periodo se aprobaron más proyectos en Honduras (171) que en Paraguay (167). Esta diferencia es mínima; puede que se deba a que los propios donantes otorgan el mismo tipo de prioridad a ambas naciones (por diagnósticos cercanos: debilidad institucional, modelo productivo excluyente). Lo que sí llama la atención es que en Honduras el periodo de la ruptura presidencia le supuso una práctica anulación de toda colaboración cuando para Paraguay no se detuvo la asistencia (sí se ralentizó en número de proyectos). La actitud, pues, ante las dos rupturas presidenciales de los donantes refleja la dureza con la que se condenó la ruptura presidencial de Honduras y la cierta flexibilidad que se tuvo frente a Paraguay. En dicho país, los proyectos llevados a cabo por ciertos donantes fueron paralizados unas semanas hasta obtener el visto bueno de los órganos de dirección para su reanudación. Aparentemente, la continuidad de la cooperación no fue debatida ni puesta en duda de manera insistente. Es igualmente sorprendente que durante la ruptura se siguieron otorgando proyectos de reforma y modernización del Estado (20 \% del total durante la ruptura presidencial), una proporción claramente inferior a la situación anterior (28.42 \%) pero superior a la del periodo del primer Gobierno posruptura presidencial.

En Honduras, la paralización llevó a un mediano aumento de los proyectos de reforma y modernización del Estado en el periodo posruptura presidencial (21.95 \% de los proyectos antes de la ruptura presidencial frente a $26.74 \%$ en posruptura presidencial). No obstante, lo que es aún más sugestivo es que los montos totales de los proyectos de reforma y modernización del Estado conocieron evoluciones más marcadas: en Honduras el valor disminuyó ostensiblemente (entre el periodo 1 y 3), y la marcha fue mucho menos marcada en Paraguay. Es decir, en Honduras hubo muchos más proyectos de reforma y modernización del Estado en el periodo posruptura presidencial que en Paraguay, pero en el segundo fueron montos más relevantes (US\$38.9 millones para Honduras frente a US\$102.6 millones en Paraguay), y eso que en ambos países el monto promedio de los proyectos aumentó entre el periodo 1 y 3 . Esto confirma igualmente el perfil de cada nación, puesto que en Honduras - a pesar de contar con más proyectos- estos suelen comprometer montos totales inferiores a los de Paraguay. Para poder ver de manera más clara los montos y las fechas de las aprobaciones de los proyectos, ver las figuras 1 y 2.

Esta elección se debe a que, si se guardaba proporcionalidad temporal, se perdían de vista los ciclos existentes en la fase de consolidación de los Gobiernos democráticos posruptura. 
Figura 1. Montos de los proyectos de cooperación internacional en Paraguay.

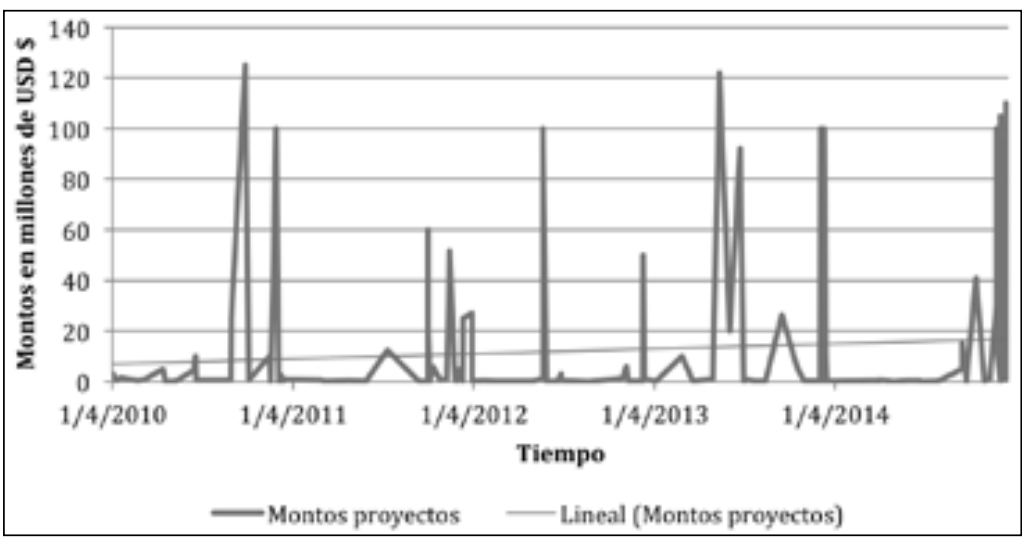

Figura 2. Montos de los proyectos de cooperación internacional en Honduras.

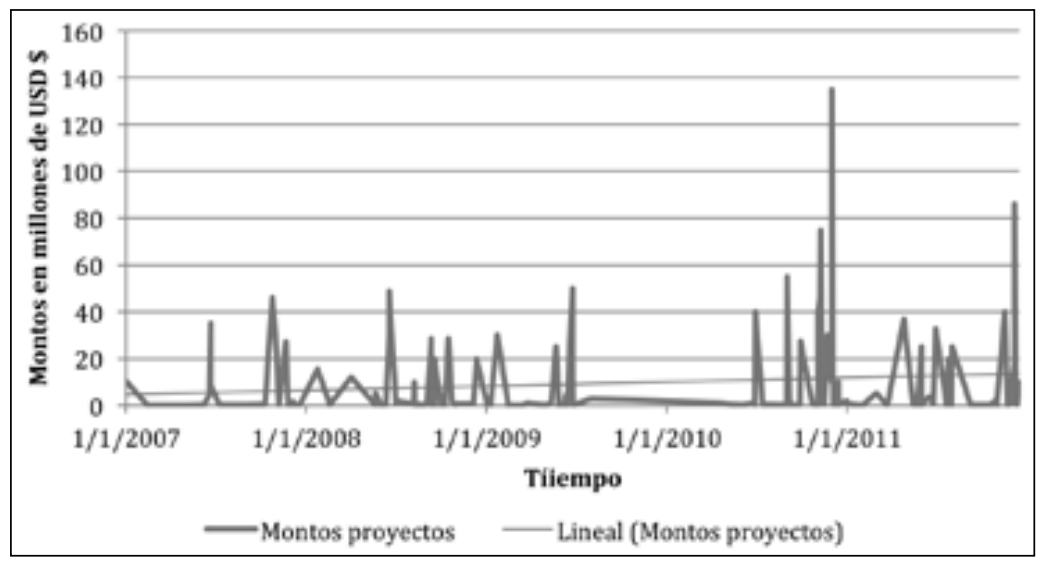

Es de acentuar que, a pesar de la crítica internacional en relación con la situación de cada país durante y después de las rupturas presidenciales, los donantes llevaron a cabo aprobaciones de proyectos por montos importantes en periodos en los cuales dialécticamente no reconocían o reconocían de manera limitada sus interlocutores. Con todo, es evidente que la condena internacional a Honduras fue respetada en los hechos por los donantes, lo que confirma y refuerza la diferencia esgrimida entre los dos países. En Honduras, el Ejército intervino para acatar las órdenes judiciales, pero su papel estigmatizó la opinión en mayor medida que en Paraguay (Bonavitta, 2011) por diversas razones: 1) un precedente de juicio político; 2) la pérdida del apoyo de aliados políticos; 3) la confrontación de Lugo con las élites económicas y trasnacionales (incluidas 
argentinas y brasileñas); 4) la ausencia del uso de fuerzas de seguridad o del orden; y 5) la aceptación -dubitativa, eso sí- por parte de Lugo del proceso.

Más allá de las razones esgrimidas, también se ha de especificar que en el caso de Lugo el desencanto era amplio (Abente-Brun, 2012) y ya existían numerosas voces que alertaban de la incapacidad para generar el cambio prometido (Turner, 2010). La destitución de Lugo tuvo, pues, derivaciones menores sobre los ciclos de ayuda, a pesar de representar una ruptura patente en un país que conocía su primera alternancia partidista real. Es a la postre sugestivo que el fin de la experiencia de Lugo fuera intuida como muy probable, tal cual lo dejaban ya ver López (2010) o inclusive ciertos columnistas de $A B C$ Color.

A la vez que se consideran los efectos de la cooperación internacional en Honduras y Paraguay, se puede tener en consideración lo que la literatura dice sobre la cooperación internacional en contextos no democráticos en otros países del mundo. Según Mattes y Rodríguez (2014), los regímenes de un solo partido o militares tienden a ser contrapartes más fiables para la cooperación. Aunque los casos estudiados no sean autocracias, la continuidad de la colaboración con Paraguay sugiere que no existían verdaderas desconfianzas (al contrario de Honduras). Precisamente, la total anulación en Honduras y la fuerte reanudación dejan suponer que lo que realmente preocupa a los donantes no es la fiabilidad de la contraparte. En efecto, para ellos existe la misma capacidad o incapacidad que el Gobierno prerruptura presidencial o de ruptura presidencial. Se trata más bien de preservar principios democráticos y, sobre todo, de respetar ciertos límites dialécticos, con el fin de evitar asociaciones (como en el pasado con los Gobiernos militares y sus correspondientes críticas).

Escribà-Folch y Wright (2010) aportan una reflexión sobre la eficacia de las sanciones económicas a regímenes autoritarios. Si bien Honduras y Paraguay no lo hayan sido durante las rupturas presidenciales, se observa que en Honduras sí se castigó al país sin fondos o proyectos. Como lo enuncian estos autores, tales sanciones no han sido eficaces a causa de reasignaciones y reforma tributaria. Lo que más llama la atención es que la primera reforma que llevó a cabo Honduras es precisamente esa: la fiscal. Lo que es aún más singular es que en este caso se inicia un periodo de ostracismo financiero y se prosigue con la ayuda de los propios donantes que habían originado indirectamente esta reforma.

Más allá de los aportes ya mencionados, la Harvard Law Review publicó en 2014 (Congressional Control of Foreign Assistance to Post-Coup States [2014]) unas apreciaciones sobre el control parlamentario de las ayudas estadounidenses en contexto de posgolpe. Centrarse en la influencia de la cooperación multilateral y dejar de lado la estadounidense oficial - fuera de la USAID - se debe a una razón bien sencilla: en Honduras la posición de los Estados fue de congelar la ayuda no humanitaria durante las rupturas presidenciales, pero la reanudó de manera inmediata una vez fue elegido 
Porfirio Lobo. Quedó demostrado que preferían una salida sencilla a esa crisis, en la que trataron de presionar para que Roberto Micheletti aceptara dialogar con Zelaya. Es hasta cierto punto evidente que la congelación de la ayuda de los Estados Unidos tuvo un efecto sobre los diálogos, pero no de manera directa sobre las reformas. En efecto, la mayoría de los proyectos de reforma se financian con organismos multilaterales, por lo que la política exterior estadounidense usa la coopreación como condicionante para la estabilización política, pero no como palanca de reforma. Eso no quita que la USAID participe en proyectos de reformas públicas.

\section{Relación entre rupturas presidenciales y reformas de gestión pública con apoyo internacional}

Se han compilado las leyes, los decretos y las resoluciones relativos a la gestión pública en Honduras y Paraguay, con el fin de verificar las correspondencias temporales y temáticas entre la realidad interna y los ciclos de la cooperación internacional.

En Honduras, se puede observar un cierto incremento en los proyectos de reforma y modernización estatal de componente más político tras la normalización posruptura presidencial. Es decir, la naturaleza de los proyectos aprobados entre 2011 y 2012 buscaba fortalecer la capacidad planeadora y presupuestaria del Estado. En el primer periodo posruptura presidencial de la presidencia de Porfirio Lobo, había, pues, un perfil bien concreto de la cooperación en relación con las reformas. Esto se ve de manera clara si se toma en cuenta la evolución de las reformas de la gestión pública (leyes y decretos principalmente): los proyectos de cooperación no coinciden con los tiempos de las reformas o son temáticas mucho más limitadas. Esto significa que la cooperación se ha centrado en restablecer y reforzar las capacidades del Estado (reforma fiscal y apoyo a la presidencia), pero no conllevó inicialmente reformas profundas. Es muy probable que estas hayan sido un primer paso para la aceleración de los proyectos observada a partir de 2013, con alcances y objetivos mucho más ambiciosos. De hecho, ya a final de 2011 se multiplicaron los proyectos del Banco Mundial y del Programa de las Naciones Unidas para el Desarrollo, tomando el relevo el del Banco Interamericano de Desarrollo, que fue el principal donante en la primera parte del Gobierno de Lobo.

Si se focaliza el análisis sobre el periodo de la segunda presidencia posruptura presidencial, se advierte que las reformas son mucho más amplias y regulares que inclusive en el periodo prerruptura presidencial. Esto deja distinguir que la reforma del Estado se ha incluido en la agenda de las políticas en una modalidad distinta desde la ruptura. La aceleración también se nutre de los proyectos de cooperación que se llevaron a cabo en el periodo prerruptura presidencial. En dicho periodo, los proyectos estaban claramente enfocados en la capacitación y en transmisión de conocimientos técnicos (tabla 4). 
Tabla 4. Principales proyectos acordados

a Honduras que superan los US\$10 millones

\begin{tabular}{|l|l|l|l|l|l|}
\hline Entidad & $\begin{array}{c}\text { N.o } \\
\text { proyecto }\end{array}$ & $\begin{array}{c}\text { Fecha de } \\
\text { aprobación }\end{array}$ & Situación & \multicolumn{1}{|c|}{ Sector } & Monto \\
\hline BM $^{\text {a }}$ & P110050 & $06 / 12 / 2011$ & Implementación & $\begin{array}{l}\text { Reforma/modernización del } \\
\text { Estado }\end{array}$ & 18.2 \\
\hline BM & P106680 & $30 / 06 / 2011$ & Implementación & $\begin{array}{l}\text { Reforma/modernización del } \\
\text { Estado }\end{array}$ & 32.8 \\
\hline BID $^{\text {b }}$ & HO-L1037 & $01 / 12 / 2010$ & Implementación & Comercio & 135 \\
\hline BM & P121220 & $09 / 11 / 2010$ & Completo & $\begin{array}{l}\text { Reforma/modernización del } \\
\text { Estado }\end{array}$ & 74.7 \\
\hline BID & HO-L1030 & $08 / 11 / 2010$ & Implementación & $\begin{array}{l}\text { Reforma/modernización del } \\
\text { Estado }\end{array}$ & 45.8 \\
\hline BID & HO-L1059 & $29 / 09 / 2010$ & Implementación & Salud & 27.5 \\
\hline BID & HO-L1031 & $24 / 06 / 2009$ & Implementación & $\begin{array}{l}\text { Medio ambiente y desastres } \\
\text { naturales }\end{array}$ & 19 \\
\hline BM & P104034 & $22 / 01 / 2009$ & Implementación & Energía & 30 \\
\hline BID & HO-L1032 & $11 / 12 / 2008$ & Completo & Inversiones sociales & 20 \\
\hline BID & HO-L1019 & $10 / 09 / 2008$ & Completo & Energía & 28.55 \\
\hline BM & P109058 & $17 / 06 / 2008$ & Implementación & Transporte & 48.6 \\
\hline BM & P101218 & $24 / 01 / 2008$ & Completo & Educación & 15.37 \\
\hline BID & HO-L1010 & $20 / 11 / 2007$ & Implementación & Agricultura y desarrollo rural & 27.1 \\
\hline PNUDc & 51185 & $01 / 01 / 2007$ & Completo & $\begin{array}{l}\text { Medio ambiente y desastres } \\
\text { naturales }\end{array}$ & 10.225 \\
\hline
\end{tabular}

aM: Banco Mundial

'BID: Banco Interamericano de Desarrollo

cPNUD: Programa de las Naciones Unidas para el Desarrollo

Estos datos sustentan al menos tres conclusiones tentativas. Primero, los proyectos de reforma y modernización del Estado suponen montos bastante altos en relación con la media constatada para el país. Segundo, el primer Gobierno posruptura firmó acuerdos que superaban incluso los que se han firmado en el segundo Gobierno posruptura presidencial o inclusive prerruptura presidencial. Se está entonces ante un aumento del interés de los donantes por colaborar o participar en proyectos de reforma. Tercero, los proyectos no tienen correspondencia temporal con las reformas propias legales, aunque sí con modificaciones internas de las administraciones públicas (entiéndase procedimientos que dependen de resoluciones).

En sístesis, se estaría por tanto ante tres momentos que sí han seguido la progresión política: 1) capacitación y fortalecimiento, 2) reforma fiscal y asesoría en planificación y 3) reformas de procesos e instituciones de la gestión pública, con el fin de mejorar la transparencia y eficiencia.

Un síntoma de que la tercera etapa sí está ligada con el diseño institucional es que la Ley para optimizar la Administración pública, mejorar los servicios a la ciudadanía y 
fortalecimiento de la transparencia en el Gobierno del 23 de enero de 2014 otorga más poderes al presidente para que pueda modificar secretarías y ministerios sin la necesidad de pasar por el Congreso. El enfoque de las reformas llevadas a cabo desde 2011, en cuyo análisis detallado no se entra aquí, se ha centrado igualmente en la necesidad de reformar la ética pública, así como la transparencia. A este nivel, vale la pena mencionar el Decreto 360 de 2013 que busca aumentar las penas y sanciones por corrupción y reestructura su investigación, así como el Decreto 177-2010 del 34/03/2010 que redefine las competencias de las municipalidades y trata de promover la gestión ética.

Es de hecho notable que muchas reformas e iniciativas de reforma hondureñas estén vinculadas con la mejoría de la transparencia y probidad de los sistemas de contratación. Es temprano para saber si los mecanismos están siendo eficaces, aunque existen dos procesos paradójicos. El primero es que se han dado pasos hacia la recentralización, aun cuando se habla de descentralización (como a través del Decreto 266 de 2013 que origina un nuevo diseño institucional ministerial y refunda las instituciones del ordenamiento territorial ${ }^{13}$ ). El segundo movimiento paradójico es el refuerzo de las competencias presidenciales después de una ruptura presidencial posibilitada por la judicialización del poder legislativo.

Una vez visto el caso de Honduras se pasa ahora a examinar Paraguay. Se advierte que los proyectos de reforma en dicho país han sido más regulares, aunque menos numerosos y de grandes sumas (mucho más que los de Honduras). Si bien no hubo ningún acuerdo significativo para reformas durante la ruptura presidencial, es probable se deba al hecho de que pocos días antes de aquellas se había firmado ya un proyecto de US\$100 millones. En el periodo posruptura presidencial, se firmó igualmente un gran proyecto, que respeta la idea de que se está ante ciclos marcados. Ahora bien, la ausencia de un gran proyecto de modernización estatal durante la ruptura presidencial no puede ser entendido en sentido de que los donantes no quisieran trabajar con el Gobierno de la ruptura presidencial (sí firmaron otro tipo de proyectos con montos significativos), sino más bien que el proyecto prerruptura presidencial seguía vigente y con fondos suficientes.

$\mathrm{Al}$ poner en perspectiva la cooperación internacional con las reformas propias de Paraguay (revisando, como para Honduras, leyes, decretos y resoluciones), se descubre que el país ha tenido una gran inestabilidad en la orientación misma de las transformaciones. Durante el periodo retenido anterior a la ruptura presidencial (de 01/01/2010 a 22/06/2012), no se dieron tantas reformas institucionales como lo pudieran haber dejado presagiar los montos de cooperación y la voluntad reformista de Lugo. Sin embargo, los

${ }^{13}$ El propio objetivo de los textos denota la tensión: los decretos ejecutivos PCM-028-2014 y PCM-029-2014 creaban la Comisión destinada a la Reforma de la Administración Pública Centralizada y Descentralizada. 
proyectos desarrollados gracias a la cooperación internacional sí se centraron en varias temáticas relevantes.

Por un lado, se iniciaron reformas destinadas a regular la política social del Gobierno tanto para las transferencias condicionadas como los subsidios para adultos en situación de pobreza o exclusión, particularmente indígenas. Por otro, se llevaron a cabo reformas en el funcionamiento de las administraciones. Un ejemplo de ello sería el Decreto 4600 del 22 de junio de 2010 con el cual se modificaban las relaciones intergubernamentales y las reglas de funcionamiento interno de todo el Ejecutivo, incluida la presidencia. Dichos cambios buscaban aumentar también la transparencia, como el Decreto 5517 del 25 de noviembre de 2010, que modificaba el sistema de subasta pública para las contrataciones en obras públicas y consultorías. Las reformas también fortalecían la lucha contra la corrupción, como el Decreto 2941 del 21 de septiembre de 2009, que creaba una unidad especial en la Procuraduría General, con el fin de regular la recuperación de los activos ilícitos.

Se trató, en definitiva, de mejorar y centralizar los sistemas de adquisiciones y gestión y aumentar la competitividad y transparencia. Las reformas del periodo prerruptura presidencial fijaron igualmente la profesionalización de las empresas públicas (sector eléctrico en especial). Es de advertir que los proyectos llevados a cabo en el periodo prerruptura presidencial pasaron, sobre todo, a través de resoluciones y decretos, no habiendo grandes leyes que reformaran la gestión pública. Esto se debe sin duda a que durante la legislatura anterior ya se habían dado sustanciosas transformaciones institucionales. El Gobierno de Lugo se centró en profundizar la profesionalización del servicio público y en sustentar el viraje social de las políticas.

En cuanto a las reformas realizadas durante la ruptura presidencial (de 23/06/2012 a 25/08/2013), no fueron muchas las decisiones. Se revirtió el diseño institucional ministerial y del Ejecutivo mediante decreto del 6 de noviembre de 2012. Por otro lado, se instauró una modificación de los criterios para las contrataciones públicas mediante el Decreto 9649 del 7 de septiembre de 2012. La actividad reformista fue mucho mayor durante el periodo retenido para el análisis de los Gobiernos posrupturas presidenciales (de 26/o8/2013 a 31/12/2014), en especial, por la recuperación de los flujos de cooperación internacional.

Los proyectos de reforma se centraron en tres grandes sectores. Por un lado, se modificaron una vez más los procedimientos para las licitaciones ${ }^{14}$ mediante el Decreto 1315 del 11 de febrero de 2014. Se reformó, además, el sistema de compensaciones y royalties de los Gobiernos departamentales y municipales a través del Decreto 1561 del 22 de mayo de 2014 que modificó la distribución fiscal del ordenamiento territorial.

${ }^{14}$ Ya se había modificado numerosas veces, inclusive en periodo prerruptura a través del Decreto 1434/2009 y el Decreto $1134 / 2009$. 
Por otro lado, se dinamizó e impulsó la inversión en infraestructura pública (mediante el Decreto 1350 del 12 de marzo de 2014 y el Decreto 1705 del 22 de mayo de 2014) y se impulsó la digitalización de la Administración pública (mediante el Decreto 1107 del 13 de enero de 2014 y, sobre todo, el Decreto 1840 del 1 de julio de 2014).

Ahora bien, teniendo en cuenta los flujos de cooperación, así como las reformas, se ve que los Gobiernos de la ruptura y posruptura presidencial han sido particularmente activos en ciertos temas, como las reglas para licitaciones. Al mismo tiempo, esas reformas han tratado de reforzar su seguimiento a causa de la clara preocupación por parte de los donantes de una posible reversión de las mejoras, así como la persistencia de falencias graves en el sistema de gestión pública paraguaya.

La progresiva informatización y revisión de procesos que se ha dado desde la ruptura presidencial dejan ver que se está de nuevo ante reformas que no revisan profundamente la estructura institucional (que la hay de todos modos), sino que tratan de hacer realidad parte de las intenciones anteriores, como dotar de vida la escuela de Administración pública. Para más precisiones sobre los proyectos que superan los US $\$ 10$ millones, ver el anexo 1.

La principales ideas de la relación entre cooperación y las reformas en Paraguay serían entonces: 1) las reformas de gestión pública se han llevado a cabo gracias a la formación y capacitación de la cooperación ligada a infraestructura; 2) dichos proyectos dotan de contenido y hacen realidad las reformas de gestión pública ya inducidas en la primera década del siglo XXI; 3) el Gobierno posruptura presidencial prosigue las reformas, pero sin modificaciones institucionales notorias o aceleración de las reformas de gestión pública; 4) no parece que las rupturas presidenciales hayan afectado la progresión ni la naturaleza de las reformas; y 5) no parece que las reformas y los proyectos hayan revertido las principales falencias de la gestión pública paraguaya, aunque es cierto que hay que esperar más años para observar réditos claros.

\section{Discusión de hipótesis y conclusiones}

Tras este breve análisis tanto del concepto de ruptura presidencial aplicado a los sucesos de Honduras y Paraguay como de la relación de dichos periodos con la cooperación y las reformas de gestión pública, se puede pasar a elaborar una discusión de la hipótesis desde tres momentos analíticos, que examinan la actitud de los actores sobre el statu quo. Se intenta elucidar si los ciclos identificados han tenido algún papel legitimador. Dente y Subirats (2014) proponen una gran variedad de variables y factores para el análisis comparado de la toma de decisiones públicas, orientado, en especial, al examen de los casos donde se habría dado policy change (cambio disruptivo o no incremental según Lindblom [1979]). Se pretende aquí ligar el análisis anterior con tres dimensiones: los recursos, los objetivos y los roles de los actores. 
Según Dente y Subirats (2014), los actores tendrían dos tipos de objetivos. Los objetivos de contenido serían las "preferencias y objetivos relativos al problema a solucionar o a la solución a adoptar" (p. 80). Los objetivos de proceso serían aquellos ligados a "las consecuencias que [...] tiene[n] sobre los recursos y sobre las posiciones de otros participantes" (p. 80). A este nivel, se podría decir que la élite política y económica de Honduras tenía objetivos de resultado, donde la ruptura presidencial buscaba frenar la aparición de un nuevo statu quo impulsado por Manuel Zelaya, quien sustentó su estrategia en atacar el viejo statu quo. En las elecciones, el Partido Libre, liderado por Xiomara Castro, se centró más en proyectar la necesidad de un statu quo distinto del buscado por su depuesto marido Manuel Zelaya. En cuanto al Gobierno de la ruptura presidencial, no tenía capacidad para legitimarse vía reformas, por lo que fueron llevadas a cabo por el primer y segundo Gobierno posruptura presidencial. Se pueden resumir las diferencias en los objetivos en la tabla 5 .

Tabla 5. Objetivos de resultado y de contenido de los actores en Honduras

\begin{tabular}{|l|l|l|}
\hline & \multicolumn{2}{|c|}{ Objetivos de resultado } \\
\hline Statu quo & \multicolumn{1}{|c|}{ Viejo statu quo } & \multicolumn{1}{c|}{ Nuevo statu quo } \\
\hline Frenar & Paso 1 para Manuel Zelaya & $\begin{array}{l}\text { Élite económica que moderniza el viejo } \\
\text { statu quo }\end{array}$ \\
\hline Impulsar & Élite política hondureña & Paso 2 para Manuel Zelaya \\
\hline & \multicolumn{2}{|c|}{ Objetivos de contenido } \\
\hline Statu quo & \multicolumn{1}{|c|}{ Viejo statu quo } & \multicolumn{1}{c|}{ Nuevo statu quo } \\
\hline Legitimar & $\begin{array}{l}\text { Primer Gobierno posruptura } \\
\text { presidencial }\end{array}$ & $\begin{array}{l}\text { Segundo Gobierno posruptura } \\
\text { presidencial }\end{array}$ \\
\hline Deslegitimar & Partido Libre y simpatizantes & Gobierno de la ruptura presidencial \\
\hline
\end{tabular}

El caso de Paraguay es distinto, puesto que el Gobierno posruptura presidencial no buscó defender abiertamente el viejo statu quo, sino hacer pasar uno similar al antiguo como nuevo. Esto llevó a que el Gobierno de la ruptura presidencial tuviera como objetivo de resultado la creación de un nuevo statu quo (como lo pretendía Lugo) a causa de su papel de opositor frente al Partido Colorado. El primer Gobierno posruptura presidencial sí tuvo una lógica de legitimación del viejo statu quo, que revertía la perspectiva del Gobierno de la ruptura presidencial (tabla 6).

Tabla 6. Objetivos de resultado y de contenido de los actores en Paraguay

\begin{tabular}{|l|l|l|}
\hline & \multicolumn{2}{|c|}{ Objetivos de resultado } \\
\hline Statu quo & \multicolumn{1}{|c|}{ Viejo statu quo } & \multicolumn{1}{c|}{ Nuevo statu quo } \\
\hline Frenar & Fuerzas sociales rurales & Paso 1 Gobierno de la ruptura presidencial \\
\hline Impulsar & Partido Colorado y élite económica & $\begin{array}{l}\text { Paso } 2 \text { Gobierno Fernando Lugo } \\
\text { Paso } 2 \text { Gobierno de la ruptura presidencial }\end{array}$ \\
\hline
\end{tabular}




\begin{tabular}{|c|l|l|}
\hline & \multicolumn{2}{|c|}{ Objetivos de contenido } \\
\hline Statu quo & \multicolumn{1}{|c|}{ Viejo statu quo } & \multicolumn{1}{c|}{ Nuevo statu quo } \\
\hline Legitimar & $\begin{array}{l}\text { Paso 2 Gobierno posruptura } \\
\text { presidencial }\end{array}$ & Apoyo internacional de la "nueva izquierda" \\
\hline Deslegitimar & Frente Guasú & Paso 1 Gobierno posruptura presidencial \\
\hline
\end{tabular}

Según Dente y Subirats (2014), los actores pueden contar con cuatro tipos de recursos: políticos, económicos, legales y cognitivos. A este nivel, se puede sintetizar el análisis del caso hondureño y añadir que la particularidad del Gobierno preruptura presidencial era justamente no tener los recursos económicos privados suficientes para compensar una oposición que defendía el statu quo con gran cantidad de recursos políticos (control parlamento y sistema de partidos), recursos económicos (apoyo de la élite empresarial al viejo statu quo), recursos legales (el parlamento judicializa la pugna) y recursos cognitivos (argumento de la defensa de la democracia a causa de la prohibición de la reelección). La relevancia de la cooperación internacional surge en el momento en el que permite que el antiguo statu quo (que regresa de la mano del primero Gobierno posruptura presidencial) se dote de los recursos legales y económicos perdidos por la institucionalidad desde la ruptura presidencial. Esto permitió al viejo statu quo asegurarse una posición de fuerza aun si los grupos pro-Zelaya contaban con grandes recursos políticos (capacidad de movilización de clases más bajas) y cognitivos (simpatía exterior por la expulsión de la presidencia).

En Paraguay, la relación de fuerzas era aún más disímil, por lo que los ciclos de cooperación internacional solo sancionaban una relación de por sí desigual. En efecto, los partidarios de Fernando Lugo en el Gobierno posruptura presidencial se encontraron con un desgaste de sus recursos políticos y económicos, además de decrecientes recursos cognitivos a causa de la normalización institucional ofrecida por el Gobierno durante la ruptura presidencial.

Dente y Subirats (2014) proponen igualmente una tipología simplificada de los roles no excluyentes entre sí: 1) el promotor, quien promueve el problema y la necesidad de intervención; 2) el director, quien orienta el proceso de toma de decisión y formulación; 3) el opositor, quien destina sus recursos a impedir las transformaciones; 4) el aliado, quien acompaña y apoya al promotor o director por interés; 5) el mediador, quien está interesado en favorecer un acuerdo entre los actores; 6) el gatekeeper, quien es capaz de bloquear el proceso decisional y así reafirmar sus intereses o posición; y 7) el filtro, quien representa y usa recursos de otros actores. Teniendo en cuenta esta clasificación, se podría decir que en Honduras la cooperación internacional para reformas sirvió de gatekeeper al tiempo que pasó a desempeñar un papel de director durante los dos Gobiernos posruptura presidencial. En Paraguay, la cooperación ejerció más bien de mediador durante la ruptura presidencial y pasó a ejercer de promotor durante el primer Gobierno posruptura presidencial. 
Se puede concluir este trabajo con tres ideas principales. Primero, las rupturas presidenciales sí tienen un impacto en los ciclos de reforma de la gestión pública al usar este instrumento como herramienta para sus objetivos de contenido y de resultado. La cooperación internacional acompaña en algunos casos la estrategia de los Gobiernos posruptura (no durante las rupturas presidenciales en sí) en cuanto al contenido pero no al resultado.

Segundo, no está claro que la ayuda internacional haya condicionado los periodos de las reformas, sino más bien que los objetivos de los resultados han condicionado la cooperación como objetivo de contenido. Es más evidente que las rupturas han afectado la proporción, el monto y el objetivo de los proyectos de reforma por parte de los donantes. Es decir, la cooperación internacional ha acompañado las estrategias de los actores sin alterarlos, por lo que no hay una relación de causalidad visible a este nivel. Sería algo parecido a lo que Turner (2014) menciona en relación con el efecto de las rupturas sobre los sistemas de partidos: tienden a recuperarse.

Tercero, es indiscutible que el trato dado a Paraguay durante la ruptura refleja la clara distinción que ha hecho la comunidad internacional con Honduras. Probablemente, la lección más sugestiva también resida en que, una vez estabilizados los países con Gobiernos reconocidos, la cooperación tienda a buscar aprovechar los nuevos ciclos políticos para generar o acompañar las reformas. Es decir, los Gobiernos nuevos, deseosos de recuperar el viejo statu quo y romper con las lógicas de insatisfacción, tenderían a aceptar proyectos de reforma con mayor facilidad o predisposición.

Independiente de las motivaciones, lo que denotan los casos de Honduras y Paraguay es que quizá se esté ante la máxima del El gatopardo, de Giuseppe Tomasi di Lampedusa: "Cambiar todo para que nada cambie". Las élites y oposiciones políticas intervinieron de manera preventiva y evitaron que la inestabilidad y las reformas de los presidentes depuestos se profundizaran; se trataba, en definitiva, de salvar el viejo statu quo. La existencia de reformas después de la ruptura presidencial serviría, pues, para proponer una alternativa a las reformas suspendidas por el quiebre, siendo conscientes las corrientes prorruptura de que han de llenar un vacío programático. La paradoja sigue siendo que la cooperación es instrumentalizada por los Gobiernos en su estrategia legitimadora y que los donantes son conscientes de esa ventana de oportunidad para mantener o relanzar sus propias agendas de intervención.

\section{Referencias}

Abente-Brun, D. (2007). Paraguay en el umbral del cambio. Ciencias Política, 27, 221-233.

Abente-Brun, D. (2012). Paraguay: crecimiento económico, conflicto social e incertidumbre política. Revista de Ciencia Política (Santiago), 32(1), 229-244. doi:10.4067/ So718-090X2012000100012 
Ajenjo Fresno, N. (2007). Honduras: nuevo gobierno liberal con la misma agenda política. Revista de Ciencia Política (Santiago), 27, 165-181. doi:10.4067/ So718-090X2007000100010

Alcántara Sáez, M. (2008). La escalada de la izquierda: la ubicación ideológica de presidentes y partidos de izquierda en América Latina. Nueva Sociedad, 217, 72-85. Recuperado de http://gredos.usal.es/jspui/bitstream/10366/18515/1/ DDPG_Escaladaizquierda.pdf

Alcántara Sáez, M. y Freidenberg, F. (2001). Los partidos políticos en América Latina. América Latina Hoy, 27, 17-35. doi:ISSN:1130-2887

Alcántara-Santuario, A. y Marín-Fuentes, V. (2013). Gobernanza, democracia y ciudadanía: sus implicaciones con la equidad y la cohesión social en América Latina. Revista Iberoamericana de Educación Superior, IV(10), 93-112.

Alcántara Sáez, M., Paramio, L., Freidenberg, F. y Déniz, J. (2006). Reformas exonómicas y consolidación de la democracia 1980-2006. Madrid: Síntesis.

Alderete, N. (2015). Los movimientos campesinos frente a la dominación y concentración del poder en Paraguay. Novapolis, 8, 57-72.

Bennett, A. y Checkel, J. T. (2014). Process tracing: From philosophical roots to best practices. En A. Bennett y J. T. Checkel (eds.), Process tracing: From metaphor to analytic tool (pp. 3-37). Cambridge: Cambridge University Press. doi:http:// dx.doi.org/10.1017/CBO9781139858472.003

Bonavitta, P. (2011). Golpe de Estado en Honduras: el discurso de Cristina Fernández. Razón y Palabra, 16(77), 18.

Boyd-Barrett, C. y Boyd-Barrett, O. (2010). Latin American 24/7 news battle for Honduras. Global Media Journal, 9(16), 1-32.

Brewer-Carías, A. R. (2009). Reforma constitucional, asamblea nacional constituyente y control judicial contencioso administrativo: el caso de honduras (2009) y el antecedente venezolano (1999). Estudios Constitucionales, 7(2), 317-353. doi:10.4067/So718-52002009000200013

Brezzo, L. M. (2010). "Reparar la nación”: discursos históricos y responsabilidades nacionalistas en Paraguay. Historia Mexicana, LX(1), 197-242.

Briceño Jiménez, R. (2011). Honduras: la deslegitimación del régimen de dominación social neoliberal: entre las contradicciones interoligárquicas y el movimiento de resistencia popular. Bajo El Volcán, 11(17), 75-90. 
Brugnoni, P. (2009). Paraguay 2008: estruendosos cambios, silenciosas permanencias. Revista de Ciencia Política, 29(2), 565-590.

Brun, D. A. (2012). Estatalidad y calidad de la democracia en Paraguay. América Latina Hoy, 6o, 43-66. Recuperado dehttp://gredos.usal.es/jspui/bitstream/10366/120693/1/ Estatalidad_y_calidad_de_la_democracia_e.pdf

Casper, B. A. y Tyson, S. A. (2014). Popular protest and elite coordination in a coup d'état. The Journal of Politics, 76(2), 548-564. doi:10.1017/So022381613001485

Cepal (2014). Panorama Social de América Latina. Santiago de Chile: Naciones Unidas.

Chasquetti, D. (2001). Democracia, multipartidismo y coaliciones en América Latina: evaluando la difícil combinación. En Tipos de presidencialismo y coaliciones políticas en América Latina (pp. 319-359). Buenos Aires: Clacso. Recuperado de http://www.redpartidos.org/files/chasquetti.pdf

Chiani, A. M. y Scartascini del Río, J. B. (coords.) (2009). La cooperación internacional: herramienta clave para el desarrollo de nuestra región. Buenos Aires: Konrad Adenauer Stiftung, Asociación Civil Estudios Populares.

Collier, D. (2011). Understanding process tracing. PS: Political Science \& Politics, 44(04), 823-830.

Coordinadora de Derechos Humanos del Paraguay (2013). Situación de los derechos a la tierra y al territorio de los pueblos indígenas en el Paraguay. Asunción.

Congressional Control of Foreign Assistance to Post-Coup States (2014). Harvard Law Review, 127(8), 2499-2520.

Crawford, G. (2001). Foreign aid and political reform: A comparative analysis of democracy assistance and political conditionality. Houndmills: Palgrave.

Dente, B. y Subirats, J. (2014). Decisiones públicas: Análisis y estudio de los procesos de decisión en políticas públicas. Barcelona: Planeta.

Domínguez, J. (2003). Disputas fronterizas en América Latina. Paceworks, 50(3), 357-391.

Duarte Recalde, L. R. (2012). Variaciones en el comportamiento electoral en Paraguay. América Latina Hoy, 6o, 117-138.

Duarte Recalde, L. R. (2013). Paraguay: interrupción al proceso de consolidación de la democracia. Revista de Ciencia Política, 33(1), 303-324.

Easton, D. (1957). An approach to the analysis of political systems. World Politics, 9(3), 383-400. 
Escribà-Folch, A. y Wright, J. (2010). Dealing with tyranny: International sanctions and authoritarian rulers. International Studies Quarterly, 54, 335-359.Figueroa Ibarra, C. (2011). Las raíces sociales del liderazgo inesperado de Mel Zelaya. Bajo El Volcán, 11(17), 103-109.

Flores López Moreira, A. R. (2009). Problemática habitacional del Paraguay: necesidad de cambio en el cambio. Centro-H, 3, 37-46. doi:10.1016/S1138-3593(01)73931-7

Freidenberg, F. (2006). La democratización de los partidos políticos en América Latina: entre la ilusión y el desencanto. En J. Thompson y F. Sánchez, Fortalecimiento de los partidos políticos en América Latina: institucionalización, democratización y transparencia (pp. 91-141). San José de Costa Rica: IIDH.

Freidenberg, F. y Alcántara Sáez, M. (coords.) (2009). Selección de candidatos, política partidista y rendimiento democrático: una introducción. México: Tribunal Electoral del Distrito Federal.

Freidenberg, F. y Levitsky, S. (2007). Organización informal de los partidos en América Latina. Desarollo Económico, 46(184), 539-568.

Fretes Carreras, L. A. (2012). Democratic consolidation in Paraguay. América Latina Hoy, $60,67-82$.

García Buchard, E. (2009). Conflictos fronterizos y antiimperialismo en las repúblicas bananeras centroamericanas: el caso de Honduras. Reflexiones, 88(2), 62-73.

Garretón, M. A. (2002). La transformación de la acción colectiva en América Latina. Revista de la Cepal, 76, 7-24.

Gerstein, J. A. (1971). El conflicto entre Honduras y El Salvador: análisis de sus causas. Foro Internacional, 11(4), 552-568.

Gómez Bueso, F. D. (2007). El estado actual de los derechos fundamentales en Honduras. Araucaria, 9(17), 118-126.

Gómez, P. S. (2014). Remesas y (sub) desarrollo en los sistemas migratorios de Bolivia y Paraguay. Ra Ximhai, 1o(1), 103-133.

Grindle, M. (2012). Good governance: The inflation of an idea. En B. Sanyal, L. J. Vale, Ch. D. Rosan, Planning ideas that matter (pp. 259-282). Cambrigde, Massachusetts: MIT Press.

Hagopian, F. (2006). Democratización: avances y retrocesos en América Latina. Revista de Ciencia Política, 26(2), 231-240.

Hochstetler, K. y Samuels, D. (2006). Rethinking presidentialism: Challenges and presidential falls in South America. Comparative Politics, 38(4), 401-418. 
Juste de Ancos, R., Soler, L. y Ortí Mata, M. (2014). Medios de comunicación, referencias nominales y poder en Paraguay. Revista Latina de Comunicación Social, 69, 229-247. doi:10.4185/RLCS-2014-1010

Kay, C. (2009). La persistencia de la pobreza rural en Honduras, Nicaragua y Bolivia: un fracaso del neoliberalismo. Nueva Sociedad, 223, 94-112.

Kruijt, D. (2001). Low intensity democracies: Latin America in the post-dictatorial era. Bulletin, 2O(4), 409-430.

Lindblom, C. E. (1979). Still muddling, not yet trough. Public Administration Review, $39(6), 517-526$.

Llanos, M. y Marsteintredet, L. (2010). Ruptura y continuidad: la caída de "Mel” Zelaya en perspectiva comparada. América Latina Hoy, 55, 173-197.

Lopes, D. B. (2007). Relações econômicas internacionais, isomorfismo institucional e democracia na América Latina: explicando as convergências (inesperadas?) entre Uruguai, Brasil e Honduras. Dados, 5o(3), 611-652. doi:10.1590/ So011-52582007000300006

López, M. (2010). La democracia en Paraguay: un breve repaso sobre los partidos políticos tradicionales, el sistema electoral y el triunfo de Fernando Lugo Méndez. Enfoques, VIII(13), 89-106.

López, M. (2012). Paraguay: de la transición a la democracia (1989-2008). Un abordaje normativo-electoral. Espacio Abierto, 21, 207-225.

López, M. (2014). Democracia en Paraguay: la interrupción del "proceso de cambio" con la destitución de Fernando Lugo Méndez (2012). Cuardernos del Cendes, 31(85), 95-119.

López, M. (2015). Acceso a los derechos electorales: Paraguay. European University Institute.

López Recinos, V. (2013). Desarrollo, migración y seguridad: El caso de la migración hondureña hacia Estados Unidos. Migración Y Desarrollo, 11(21), 65-105.

Macías Ruano, M., Ogando Caníbal, O. y Rodríguez Prado, B. (2009). La evolución de la pobreza en Honduras, 1995-2005. Análisis Económico, XXIV(55), 179-205.

Mahoney, J. (2011). Liberalismo radical, reformista y frustrado: orígenes de los regímenes nacionales en América Central. América Latina Hoy, 57, 79-115.

Mahoney, J. (2012). The logic of process tracing tests in the social sciences. Sociological Methods y Research, 41(4), 570-597. doi:10.1177/0049124112437709 
Marsteintredet, L., Llanos, M. y Nolte, D. (2013). Paraguay and the politics of impeachment. Journal of Democracy, 24(4), 110-123.

Mattes, M. y Rodríguez, M. (2014). Autocracies and international cooperation. International Studies Quarterly, 58, 527-538. doi:10.1111/isqu.12107

Medina, J. y Franco, L. (2006). Reflexiones sobre los procesos de integración y las relaciones laborales en América Latina. Cuadernos de Relaciones Laborales, 24, 9-25. Recuperado de http://revistas.ucm.es/index.php/CRLA/article/view/ CRLA0606120009A/32321

Medina, L. (2013). Una interfaz transfronteriza compleja. El caso del golfo de Fonseca: El Salvador, Honduras y Nicaragua. Liminar: Estudios Sociales y Humanísticos, $X I(2), 54-69$.

Mollett, S. (2006). Race and natural resource conflicts in Honduras: The miskito and garifuna struggle for lasa pulan. Latin American Research Review, 41(1), 76-101. doi:10.1353/lar.2006.0012

Morlino, L. (2004). What is a "good" democracy? Democratization, 11, 10-32. doi:10.1 080/13510340412331304589

Mustapic, A. M. (2006). América Latina: las renuncias presidenciales y el papel del Congreso. Política, 47, 55-70. Recuperado de http://www.revistadematematicas.uchile.cl/index.php/rupturas presidenciales/article/viewFile/16782/17478

O’Donnell, G., Vargas, J. y Munck, G. (2004). La democracia en América Latina: hacia una democracia de ciudadanas y ciudadanos. Buenos Aires: PNUD.

O’Donnell, G. (1994). Delegative democracy. Journal of Democracy, 5(1), 55-69. doi:ISSN 0101-3300

Orozco, M. (2003). The impact of migration in the Caribbean and Central American region. Focal. Recuperado de http://www.focal.ca/pdf/migration_Orozco_impact \%20migration \%20Caribbean \%20Central \%20American \%2oregion_ March \%202003_FPP-03-03.pdf

Otero Felipe, P. (2013). El sistema de partidos de Honduras tras la crisis política de 2009: ¿el fin del bipartidismo? Colombia Internacional, 79, 249-287.

Parsons, W. (2007). Políticas públicas: una introducción a la teoría y la práctica del análisis de políticas públicas. México: Miño y Dávila.

Pérez, C. R., Soto de la Rosa, H. y Pellandra, A. (2012). Integración social en Centroamérica. México: Naciones Unidas. Recuperado de http://www.giz-cepal. 
cl/newsletter/newsletter_enero_2013/integracion_social_en_centroamerica_version_final.pdf

Pérez-Liñán, A. (2000). ¿Juicio político o golpe legislativo?: sobre las crisis constitucionales en los años noventa. América Latina Hoy, 26, 67-74.

Pérez-Liñán, A. (2012). Political elites, democratic breakdown, and presidential instability in Latin America. Ponencia presentada en la 22 nd International Political Science Association (IPSA) Conference, Madrid.

Pine, A. y Vivar, D. (2011). Tegucigolpe: donde se cruzan los caminos, se unen fronteras y divergen las percepciones. Colombia Internacional, 73, 25-47. doi:10.7440/ colombiaint73.2011.02

Powell, J. (2012). Determinants of the attempting and outcome of coups d'état. Journal of Conflict Resolution, 56(6), 1017-1040. doi:10.1177/0022002712445732

Prera, A. J. (2012). The effects of economic integration and political instability in Central America. Latin American Business Review, 13(2), 121-139. doi:10.1080/10978 526.2012 .700274

Santiso, C. y Von Horoch, J. (2015). Resoluciones para el 2015: tres prioridades para mejorar la gestión pública y los servicios al ciudadano. Recuperado de http:// blogs.iadb.org/gobernarte/2015/o1/o7/resoluciones-para-el-2015-tres-prioridades-para-mejorar-la-gestion-publica-y-los-servicios-al-ciudadano/

Sartori, G. (1994). Neither presidentialism nor parliamentarism. En J. J. Linz y A. Valenzuela (eds.), The failure of presidential democracy. Baltimore: Johns Hopkins University Press.

Serrafero, M. D. (1996). El “impeachment” en América Latina: Argentina, Brasil y Venezuela. Revista de Estudios Políticos, 92, 137-162.

Sosa Iglesias, J. E. (2014). Honduras: entre criminalidad, enfrentamiento mediático, protesta social y resultados electorales cuestionados. Revista de Ciencia Política, 34(1), 203-220.

Taylor-Robinson, M. M. (2006). La política hondureña y las elecciones de 2005. Revista de Ciencia Política, 26(1), 114-124. doi:10.4067/So718-090X2006000100006

Thyne, C. L. y Powell, J. M. (2014). Coup d'état or coup d'autocracy?: How coups impact democratization, 1950-2008. Foreign Policy Analysis, o, 1-22. doi:10.1111/fpa.12046

Turner, B. (2010). Paraguay: muchas novedades y poco cambio. Revista de Ciencia Política, 30(2), 439-450. 
Turner, B. (2014). Paraguay: la vuelta del Partido Colorado al poder. Revista de Ciencia Política, 34(1), 249-266.

Valenzuela, A. (2008). Presidencias latinoamericanas interrumpidas. América Latina Hoy, 49, 15-30. Recuperado de http://gredos.usal.es/jspui/bitstream/10366/72674/1/Presidencias_latinoamericanas_interrumpi.pdf

Varol, O. O. (2012). The democratic coup d'état. Harvard International Law Journal, 53(2), 292-356. doi:10.1525/sp.2007.54.1.23.

Waring, J. (2014). Restratification, hybridity and professional elites: Questions of power, identity and relational contingency at the points of "professional-organisational intersection”. Sociology Compass, 5, 688-704. 


\section{Anexo}

Principales proyectos acordados a Honduras que superan los US $\$ 10$ millones

\begin{tabular}{|c|c|c|c|c|c|}
\hline Entidad & $\begin{array}{c}\mathbf{N} .^{\circ} \\
\text { proyecto }\end{array}$ & $\begin{array}{c}\text { Fecha de } \\
\text { aprobación }\end{array}$ & Situación & Sector & Monto \\
\hline $\mathrm{BID}^{\mathrm{a}}$ & PR-L1029 & $15 / 12 / 2014$ & Aprobado & Agua y saneamiento & 110 \\
\hline BID & PR-L1080 & $03 / 12 / 2014$ & Aprobado & Transporte & 105 \\
\hline BID & PR-L1081 & $26 / 11 / 2014$ & Aprobado & Mercados financieros & 30 \\
\hline BID & PR-L1077 & $26 / 11 / 2014$ & Aprobado & Inversiones sociales & 20 \\
\hline BID & PR-L1084 & $26 / 11 / 2014$ & Aprobado & Transporte & 100 \\
\hline BID & PR-L1087 & $15 / 10 / 2014$ & Aprobado & Empresas privadas y desarrollo de pymes & 40.93 \\
\hline BID & PR-L1089 & $17 / 09 / 2014$ & Completo & Comercio & 15.03 \\
\hline $\mathrm{BM}^{\mathrm{b}}$ & $\mathrm{p} 117043$ & $13 / 12 / 2013$ & Completo & Reforma/modernización del Estado & 100 \\
\hline BM & p148504 & $05 / 12 / 2013$ & Implementación & Agricultura y desarrollo rural & 100 \\
\hline BID & PR-L1078 & $18 / 09 / 2013$ & Aprobado & Empresas privadas y desarrollo de pymes & 26.25 \\
\hline BID & PR-L1071 & $26 / 06 / 2013$ & Completo & Agricultura y desarrollo rural & 92 \\
\hline BID & PR-L1076 & $05 / 06 / 2013$ & Aprobado & Empresas privadas y desarrollo de pymes & 20 \\
\hline BID & PR-L1075 & $15 / 05 / 2013$ & Aprobado & Transporte & 122 \\
\hline BID & PR-L1058 & $12 / 12 / 2012$ & Implementación & Energía & 50 \\
\hline BID & PR-L1047 & $23 / 05 / 2012$ & Aprobado & Reforma/modernización del Estado & 100 \\
\hline BID & PR-L1051 & $01 / 01 / 2012$ & Implementación & Inversiones sociales & 27 \\
\hline BID & PR-L1054 & $17 / 11 / 2011$ & Aprobado & Industria & 51.75 \\
\hline BID & PR-L1062 & $17 / 11 / 2011$ & Aprobado & Mercados financieros & 50 \\
\hline BID & PR-L1047 & $23 / 05 / 2012$ & Aprobado & Reforma/modernización del Estado & 100 \\
\hline BID & PR-L1051 & $01 / 01 / 2012$ & Implementación & Inversiones sociales & 27 \\
\hline BID & PR-L1054 & $17 / 11 / 2011$ & Aprobado & Industria & 51.75 \\
\hline BID & PR-L1062 & $17 / 11 / 2011$ & Aprobado & Mercados financieros & 50 \\
\hline BID & PR-G1001 & $03 / 10 / 2011$ & Implementación & Agua y saneamiento & 60 \\
\hline BID & PR-L1060 & $03 / 10 / 2011$ & Implementación & Agua y saneamiento & 20 \\
\hline BID & PR-L1049 & $13 / 07 / 2011$ & Implementación & Reforma/modernización del Estado & 12.5 \\
\hline $\mathrm{BM}$ & p114971 & $30 / 11 / 2010$ & Implementación & Energía & 100 \\
\hline BID & PR-X1003 & $24 / 11 / 2010$ & Implementación & Agua y saneamiento & 40 \\
\hline BID & PR-L1044 & $29 / 09 / 2010$ & Aprobado & Transporte & 125 \\
\hline BID & PR-L1059 & $01 / 09 / 2010$ & Aprobado & Mercados financieros & 25 \\
\hline BM & p113457 & $05 / 05 / 2009$ & Completo & Reforma/modernización del Estado & 100 \\
\hline BM & p095235 & $14 / 04 / 2009$ & Implementación & Agua y saneamiento & 64 \\
\hline BM & p088799 & $29 / 01 / 2008$ & Implementación & Agricultura y desarrollo rural & 37.5 \\
\hline
\end{tabular}

a BID: Banco Interamericano de Desarrollo

${ }^{b}$ BM: Banco Mundial 